\title{
CEsifo \\ WORKING

\section{How Altruistic Is Indirect Reciprocity? - Evidence from Gift-Exchange Games in the Lab}

Johannes Becker, Daniel Hopp, Karolin Süß 


\section{Impressum:}

CESifo Working Papers

ISSN 2364-1428 (electronic version)

Publisher and distributor: Munich Society for the Promotion of Economic Research - CESifo

$\mathrm{GmbH}$

The international platform of Ludwigs-Maximilians University's Center for Economic Studies and the ifo Institute

Poschingerstr. 5, 81679 Munich, Germany

Telephone +49 (0)89 2180-2740, Telefax+49 (0)89 2180-17845, email office@cesifo.de

Editor: Clemens Fuest

https://www.cesifo.org/en/wp

An electronic version of the paper may be downloaded

- from the SSRN website: www.SSRN.com

- from the RePEc website: $\quad$ www.RePEc.org

- from the CESifo website: https://www.cesifo.org/en/wp 


\title{
How Altruistic is Indirect Reciprocity? - Evidence from Gift-Exchange Games in the Lab
}

\begin{abstract}
Indirect reciprocity is defined as a specific kind of behavior: An agent rewards or penalizes another agent for having behaved kindly or unkindly toward a third party. This paper analyzes the question of what drives indirect reciprocity: Does the agent reward or penalize because she (altruistically) cares for the third party? Or does she take the other agent's behavior as a signal of how the latter would treat her if they met? In order to measure the relative importance of the altruism motive versus the signaling motive, we consider a gift-exchange game with three players: an employer pays wages to a worker and a coworker, before the worker (but not the coworker) may reciprocate by exerting effort. We offer a theoretical framework to analyze both motives for indirect reciprocity and run a series of lab experiments. The treatments manipulate the worker's information on wages. We find that, if only the coworker's wage is observable, the worker's effort increases in the coworker's wage. In contrast, if the worker can observe her own wage, the coworker's wage does not affect worker effort at all. We interpret this as support for the signaling motive: Indirect reciprocity is rather a byproduct of direct reciprocity than an act of altruism.
\end{abstract}

JEL-Codes: A130, C920, D910, J310.

Keywords: gift-exchange, indirect reciprocity, signaling.

\author{
Johannes Becker* \\ Institute of Public Economics \\ University of Münster / Germany \\ johannes.becker@wiwi.uni-muenster.de
}

\author{
Daniel Hopp \\ Institute of Public Economics \\ University of Münster / Germany \\ daniel.hopp@wiwi.uni-muenster.de
}

Karolin Süß

Ruhr Graduate School in Economics and Chair of Quantitative Methods in Economics, University of Duisburg-Essen / Germany karolin.suess@uni-due.de

*corresponding author 


\section{Introduction}

Indirect reciprocity is believed to provide a powerful mechanism that induces stable levels of cooperation in large, anonymous groups such as modern societies (Herne et al., 2013). The notion of indirect reciprocity has first been addressed by Alexander (1987) and generally refers to rewards or punishments by an agent in response to interactions between other agents (see e.g. Falk and Fischbacher (2006)). ${ }^{1}$ To be precise, in a group of three individuals (A, B and C), individual C's behavior is characterized by indirect reciprocity if she behaves kindly (unkindly) toward A in response to A's kind (unkind) behavior toward B. That is, C is willing to invest own resources in order to sanction an action she is not directly affected by.

A large experimental and theoretical literature focuses on the existence ${ }^{2}$, evolution ${ }^{3}$ and stability ${ }^{4}$ of indirect reciprocity. However, there are only a few contributions on the question what drives indirectly reciprocal behavior. Reciprocal behavior is often rationalized through intention-based ${ }^{5}$ preferences (Rabin, 1993). ${ }^{6}$ In the context of indirect reciprocity, intention-based means that individual A's payoff increases (decreases) C's utility if C perceives A to be kind (unkind). Observing A's behavior toward $\mathrm{B}$ allows for an update on A's kindness (as perceived by C). Based on the update, $\mathrm{C}$ has an incentive to reward or punish A - e.g. if A's behavior is interpreted as well-intended, her payoff enters positively into C's utility function.

This paper focuses on the nature of the update: what exactly does $\mathrm{C}$ perceive as well-intended or kind? We consider two polar cases. First, if C were completely selfish, only A's behavior toward C would matter. In this case, A's behavior toward B is only interesting if it provides a signal how A would treat $\mathrm{C}$ if they met. Indirect reciprocity, 'in this sense, would just be a side-effect of direct reciprocity' as it 'serves as a noisy signal of [A's] kindness towards [C]' (Engelmann and Fischbacher, 2009, p.406). ${ }^{7}$ Similarly, Alexander (1987) considers 'indirect reciprocity as a consequence of direct reciprocity occurring in the presence of interested audiences [...] who continually evaluate the members

\footnotetext{
${ }^{1}$ Such behavior is sometimes referred to as downstream indirect reciprocity (Nowak and Sigmund, 2005). Throughout the paper, we define reciprocity as a specific kind of behavior based on preferences rather than being a preference itself. For similar approaches, see e.g. Fehr et al. (1998b), Gächter and Falk (2002), Falk and Fischbacher (2006), Charness and Levine (2007) and Dariel and Riedl (2017).

${ }^{2}$ See Diekmann (2004), Cox and Deck (2005) and Moreno-Okuno and Mosiño (2017).

${ }^{3}$ See Axelrod and Hamilton (1981), Nowak and Sigmund (2005), Boyd and Richerson (1989), Lotem et al. (1999), Leimar and Hammerstein (2001), Sethi and Somanathan (2001), Bowles and Gintis (2004), Barta et al. (2011), Barta (2016), Enke (2019), Dufwenberg and Kirchsteiger (2019) and Ito et al. (2019).

${ }^{4}$ See Güth (1995), Nowak and Sigmund (1998), Fishmann et al. (2001), Leimar and Hammerstein (2001), Berger and Grüne (2016) and Tanaka et al. (2016).

${ }^{5}$ In contrast, Fehr and Schmidt (1999), Levine (1998) and Bolton and Ockenfels (2000) assume other-regarding preferences that are outcome-based.

${ }^{6}$ Charness and Rabin (2002), Falk and Fischbacher (2006) and Cox et al. (2007) offer models that combine outcomebased and intention-based preferences, see also Dufwenberg and Kirchsteiger (2019) and Dufwenberg and Kirchsteiger (2000) for an application to the labor market. Falk et al. (2008) find that intentions are crucial to explain the experimental data.

${ }^{7}$ Behavior is characterized by direct reciprocity when $\mathrm{C}$ reciprocates to A's behavior toward C.
} 
of their society as possible future interactants' (pp. 93/94). Second, if C were (partly) altruistic, kindness would be defined more broadly and include A's behavior toward B and others (see e.g. Nowak and Sigmund (2005)). Then, even if C knew for certain how A would treat C, A's behavior toward B would still be relevant since $\mathrm{C}$ cares about B's payoff. ${ }^{8}$

In order to rationalize reciprocal behavior, we use the generalized model from Dufwenberg and Kirchsteiger (2004) and augment it by an altruism term. The model is then used to clearly define the signaling motive and the altruism motive for indirect reciprocity. We design an experiment that allows disentangling the two motives for rewarding or penalizing other agents' behavior.

We propose a classic gift-exchange game ${ }^{9}$ with three players: an employer, a worker and a coworker. The employer may set different wages for the worker and the coworker. Only the worker may reciprocate by choosing an effort level (that increases the employer's payoff). The experimental treatments vary the information provided to the worker who is informed about either (i) only her own wage or (ii) only her coworker's wage or (iii) both wages. These three different information settings allow testing for the impact of the coworker's wage on effort levels with and without information on the worker's own wage. If indirect reciprocity were rooted in altruistic preferences, a positive relationship between effort and the coworker's wage should occur irrespective of the available information. In contrast, if indirect reciprocity is driven by selfishness and the employer's wage for the coworker is just a signal, the coworker's wage is not expected to affect the effort once the own wage becomes observable (as in this case, the employer's kindness toward the worker does not need to be deduced from the coworker's wage).

We find strong support for the signaling motive. The worker's effort increases in the coworker's wage only when her own wage is unobservable. The worker (correctly) anticipates that her own wage is positively correlated with the coworker's wage. If both wages can be observed, the coworker's wage seems to be irrelevant for the worker's effort choice.

One concern with this interpretation is that the treatments differ in the complexity level. When both wages are observable, participants need to cope with two pieces of information and may opt to focus on just one of them: their own wage. To address this concern, we consider an additional treatment that allows for comparisons between decisions with similar complexity level. We let the computer randomly determine the worker's wage (while the employer keeps setting the coworker's wage). Thus, the worker's own wage does not allow for conclusions about the employer's kindness. In this setting, we find that the worker's effort increases in the coworker's wage - the worker seems to take the coworker's wage as

\footnotetext{
${ }^{8} \mathrm{An}$ alternative is to assume that individuals intentionally use indirect reciprocity in order to achieve a certain goal, e.g. to establish or enforce social norms, see e.g. Fehr et al. (1998b) and Reuben and Riedl (2013). In this case, C does not care about A's specific behavior toward B, but anticipates that letting this behavior unsanctioned may erode the implicit rules of the group.

${ }^{9}$ The theory of gift-exchanges (Akerlof (1982) and Akerlof and Yellen (1990)) suggests that employers may overcome moral hazard problems in labor relations where effort is non-enforceable by motivating workers by paying high(er) wages. In theory, employees reciprocate this gift in bilateral gift-exchange games by exerting higher effort levels. Fehr et al. (1993) design a gift-exchange experiment and find that above-minimum-level wages increase workers' effort. See also Fehr et al. (1997), Fehr et al. (1998a), Charness and Haruvy (2002), Gächter and Falk (2002) and Dariel and Riedl (2017) for further support and Fehr and Gächter (2000) for a survey of bilateral gift-exchange games. More recent papers use field experiments to analyze the importance of direct reciprocity in labor market environments, see Bellemare and Shearer (2009) and, for mixed results, Gneezy and List (2006) and Kube et al. (2012). Alternative experimental settings to analyze reciprocal behavior are sequential dictator games, see e.g. Herne et al. (2013) and Ito et al. (2019), and helping games, see e.g. Wedekind and Milinski (2000), Greiner and Levati (2005), Seinen and Schram (2006) and Engelmann and Fischbacher (2009).
} 
a signal of how the employer would behave toward her if she were able to choose the worker's wage level. On a side note, these findings also inform about the question whether reciprocity is primarily based on outcomes or on intentions: When the computer (instead of the employer) determines wages, the worker increases her effort in response to a higher wage (although the latter is not due to the employer's kindness) - however, not as strongly as when the employer sets the wage level.

Interestingly, when the employer knows which treatment is played, she increases the coworker's wage even when the worker can observe both wages. The employer seems to (falsely) assume that workers respond to the coworker's wage even when their own wage is known.

We are not the first to consider a gift-exchange game with more than one (gift receiving) worker. Akerlof (1982) himself suggests that due to the 'acquire[d] sentiment for each other' (p. 543), employees care about their coworker's wage and thus increase effort in their own and their coworker's wage (see also Akerlof and Yellen (1990)). ${ }^{10}$ In a setting where the employer pays the same wage to all workers, Maximiano et al. (2007) do not find significant behavioral differences between a bilateral gift-exchange game and a game with one employer and four employees. Charness and Levine (2007) let the employer pay different wages to workers who differ in productivities. In this setting, workers react strongly to their own wage but seem to be indifferent toward their coworker's wage. Rivas (2009) tests the impact of the coworkers' wages on effort when the respective productivity levels are public information. In this experiment, inequality in wages only affects effort negatively if wages are remarkably unfair and the high productivity worker earns 30 times more than the low productivity worker. Gächter and Thöni (2010) explicitly test whether workers evaluate the fairness of their wage relatively to the wages in a reference group that is most likely to be their coworkers. In line with Akerlof and Yellen (1990), they find that on average, workers' effort increases in their own wage as long as their wage falls short of their coworkers' wages and that they do not further increase effort if they earn more than their reference group. However, only 15 percent of the participants increase their effort in response to higher coworkers' wages. ${ }^{11}$ Gross et al. (2015) find that highly productive workers decrease effort if they do not earn more than their less productive coworkers. ${ }^{12}$

The evidence for indirect reciprocity in real world settings is mixed as well. Heinz et al. (2017) find lower levels of productivity of participants in a field experiment after their colleagues have been treated unfair. In contrast, Cohn et al. (2014) find no effect on performance when the own wage is constant but the coworker's wage is cut.

To summarize, most existing studies do not find strong support for indirect reciprocity in multi-player gift-exchange experiments since many participants seem to be indifferent toward their coworker's wellbeing. This is different in helping games where indirect reciprocity is observed more frequently. ${ }^{13}$ One reason for this difference could be that, in most gift-exchange games considered so far, the workers know their own wage, i.e. the employers' behavior toward them can be observed. In helping games,

\footnotetext{
${ }^{10}$ One implication may be that a profit maximizing firm has an incentive to compress wages in order to elicit high levels of effort.

${ }^{11}$ In a series of experiments, Gächter et al. $(2012,2013)$ let employees choose their effort sequentially. In their setting, instead of equalizing payoffs, subjects try to mimic other participant's behavior, meaning their effort. Pay comparison plays a much weaker role in predicting reciprocal behavior than the comparison of effort levels does.

${ }^{12}$ This result is also supported by Bolton and Werner (2016), who find that highly productive workers demand higher wages than less productive workers to exert the same level of effort. Similarly, employees with high effort levels expect to obtain substantially higher wages than their coworkers who exert lower effort levels (Abeler et al., 2010).

${ }^{13}$ See Wedekind and Milinski (2000), Greiner and Levati (2005), Seinen and Schram (2006) and Engelmann and Fischbacher (2009).
} 
however, there is no direct interaction with the receiver and therefore the decision is solely based on her image score. ${ }^{14}$ This paper contributes to the literature by focusing on the interference of direct and indirect reciprocity. It provides an explanation (the signaling motive) for the contradictory results from multi-player gift-exchange games and helping games.

In the next section, we describe the experimental set-up and develop a model to clarify and distinguish altruism and selfishness as potential drivers of indirect reciprocity. Sect. 3 presents the results of the main experiment, Sect. 4 some robustness checks. The last section discusses and summarizes our main findings.

\section{Theory and experimental design}

In this section, we outline the theory as well as the experimental design.

\subsection{Theory}

To distinguish the two motives for indirect reciprocity, we start considering a more general decision setting of the following type. There are three agents, labeled $M, W$ and $C$. At the first stage, agent $M$ chooses an action $r_{W} \in \mathbb{R}_{+}$and an action $r_{C} \in \mathbb{R}_{+}$. These two actions imply a cost for $M$ and affect the material payoffs, $\pi_{W}$ and $\pi_{C}$ of agents $W$ and $C$, respectively. At the second stage, agent $W$ decides on $e \in \mathbb{R}_{+}$that is costly for $W$ and affects $M$ 's material payoff, $\pi_{M}$.

Figure 2.1: Gift-exchange game with three players.
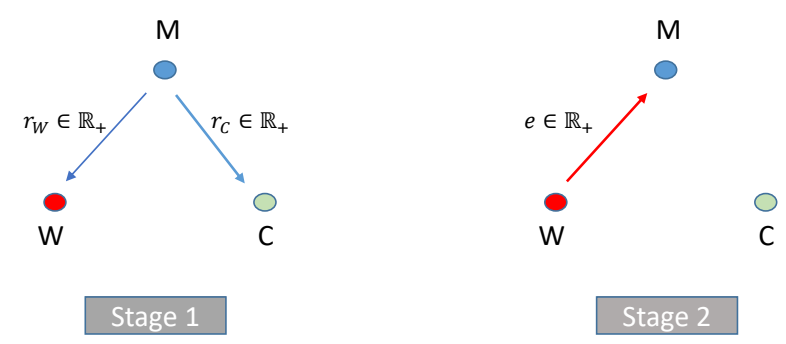

Such a setting encompasses a range of typical situations of direct reciprocity (where $W$ responds to $M$ 's choice of $r_{W}$ ) and indirect reciprocity (where $W$ responds to $r_{C}$ ), e.g. gift-exchange games and helping games. These typical situations usually have the feature that, with purely selfish players, there is a subgame perfect Nash equilibrium with $\left(r_{W}^{*}, r_{C}^{*}, e^{*}\right)=(0,0,0)$. However, in lab experiments, the actually chosen levels of $r_{W}, r_{C}$ and $e$ are significantly different from zero. This may be due to altruism or, if $e$ responds to $r_{W}$ and/or $r_{C}$, due to preferences that induce direct or indirect reciprocity.

\footnotetext{
${ }^{14}$ This image score reflects how often the current receiver has helped other participants in the experiment before and, therefore, may be interpreted as a signal for the receiver's willingness to act kindly toward the donor if they had a direct interaction.
} 
We consider a specific variant of the above decision setting: a gift-exchange game. We refer to $M$ as the manager, to $W$ as the worker, to $C$ as the coworker, to $r_{W}$ and $r_{C}$ as wage rates and to $e$ as effort. Given $r_{W}, r_{C}$ and $e$, the agents' material payoffs $\pi_{i}$ are $\pi_{M}=v(e)-r_{C}-r_{W}$ and $\pi_{W}=r_{W}-k(e)$ and $\pi_{C}=r_{C}$. We will assume that $v^{\prime}(e),^{\prime}(e)>0, v^{\prime \prime}(e) \leq 0$ and $k^{\prime \prime}(e) \geq 0$.

In order to analyze reciprocal behavior, we focus on the worker $W$ who may respond to $M$ 's choices of $r_{W}$ and $r_{C}$ at stage 2. Rabin (1993) argues that reciprocal behavior can be rationalized through a utility function that depends not only on material outcomes but also on intention-dependent fairness considerations. ${ }^{15}$ We assume a generalized version of the utility function (for the worker) proposed by Dufwenberg and Kirchsteiger (2004):

$$
U_{W}=\pi_{W}+Y \cdot \underbrace{\lambda_{W}\left(r_{W}, r_{C}, e^{b}\right)}_{M \text { 's kindness as perceived by } W} \cdot \underbrace{\kappa_{W}\left(e, r_{W}, r_{C}\right)}_{W \text { 's kindness toward } M}
$$

where $Y>0$ is a shift parameter. The worker's utility has, thus, two parts. The first part reflects the worker's own material payoff, $\pi_{W}$. The second part depends, apart from $Y$, on two variables. $\kappa_{W}\left(e, r_{W}, r_{C}\right)$ measures how kind $W$ is toward $M$. The higher $W$ 's choice of $e$, the kinder is $W$ 's behavior toward $M$. The notion of kindness is potentially scaled by the levels of $r_{W}$ and $r_{C} \cdot{ }^{16}$ Dufwenberg and Kirchsteiger (2004) suggest a specific functional form of $\kappa($.$) that we will adopt here$ to illustrate our main point:

$$
\kappa_{W}\left(e, r_{W}, r_{C}\right)=\pi_{M}\left(r_{W}, r_{C}, e\right)-\pi_{M}\left(r_{W}, r_{C}, \bar{e}\right)=v(e)-v(\bar{e})
$$

where $\bar{e}$ is a level of effort deemed to be the kindness threshold (in the sense that $e>\bar{e}$ is kind, and $e<\bar{e}$ is unkind behavior $).{ }^{17}$

The variable $\kappa_{W}($.$) is multiplied by a variable \lambda_{W}\left(r_{W}, r_{C}, e^{b}\right)$ that indicates to which degree the worker $W$ wants to be kind toward the manager $M$. For instance, if $r_{W}$ and (possibly) $r_{C}$ have been chosen at high levels and are thus considered kind, $\lambda_{W}\left(r_{W}, r_{C}, e^{b}\right)$ is positive and large, implying that $W$ has an incentive to exert high effort to benefit $M$. In contrast, if $r_{W}$ and (possibly) $r_{C}$ are low and regarded as unkind, $\lambda_{W}\left(r_{W}, r_{C}, e^{b}\right)$ may even be low or negative implying that the worker wants to set $e$ to zero (or even harm the manager, if this were possible). Again, the notion of $M$ 's kindness toward $W$ is potentially scaled by the expected effort exerted by $W$ at the second stage. Since this belief is not observable, $W$ needs to form a belief on $M$ 's belief on $W$ 's choice of $e$ (denoted by $e^{b}$ ).

\footnotetext{
${ }^{15}$ It is, thus, a "psychological game" in the sense of Geanakoplos et al. (1989).

${ }^{16}$ For instance, if $M$ has chosen high wage rates $r_{W}$ and $r_{C}$, a moderate effort choice $e$ may be regarded as unkind, whereas the same level of effort may be perceived as kind if $r_{W}$ and $r_{C}$ are low.

${ }^{17}$ In contrast, Rabin (1993) assumes that the difference between $M$ 's actual material payoff and the fair benchmark is normalized by the fair benchmark itself:
}

$$
\kappa_{W}\left(e, r_{W}, r_{C}\right)=\frac{\pi_{M}\left(r_{W}, r_{C}, e\right)-\pi_{M}\left(r_{W}, r_{C}, \bar{e}\right)}{\pi_{M}\left(r_{W}, r_{C}, \bar{e}\right)}
$$


In parallel to the above, Dufwenberg and Kirchsteiger (2004) $\operatorname{propose}^{18} \lambda_{W}\left(r_{W}, r_{C}, e^{b}\right)=\pi_{W}\left(r_{W}, e^{b}\right)-$ $\pi_{W}\left(\bar{r}_{W}, e^{b}\right)=r_{W}-\bar{r}_{W}$ where $\bar{r}_{W}$ is a wage rate level deemed to be the kindness threshold. To allow for the possibility that $W$ 's attitude toward $M$ also depends on her behavior toward $C$, we augment the above functional form as follows:

$$
\begin{aligned}
\lambda_{W}\left(r_{W}, r_{C}, e^{b}\right) & =\pi_{W}\left(r_{W}, e^{b}\right)-\pi_{W}\left(\bar{r}_{W}, e^{b}\right)+\alpha\left[\pi_{C}\left(r_{C}\right)-\pi_{C}\left(\bar{r}_{C}\right)\right] \\
& =r_{W}-\bar{r}_{W}+\alpha\left[r_{C}-\bar{r}_{C}\right]
\end{aligned}
$$

where $\alpha$ is a measure of $W$ 's altruism (or resentment) toward $C$.

At stage $2, r_{W}$ and $r_{C}$ have been determined and $e^{b}$ is only relevant at the time the wage rates are set. As a consequence, $\kappa_{W}($.) only varies in $e$. The utility-maximizing choice of $e$ is therefore implied by

$$
\frac{\partial U_{W}}{\partial e}=-k^{\prime}(e)+Y \lambda_{W}\left(r_{W}, r_{C}, e^{b}\right) \frac{\partial \kappa_{W}\left(e, r_{W}, r_{C}\right)}{\partial e} \leq 0
$$

Provided that $\frac{\partial \kappa_{W}(.)}{\partial e}>0$, the optimal effort $e^{*}$ is zero if $\lambda_{W}($.$) is sufficiently small, { }^{19}$ i.e. if the worker does not care about the manager or, worse, wants to harm the manager because she feels treated badly. If $\lambda_{W}\left(r_{W}, r_{C}, e^{b}\right)>0$ and there is an inner solution, the worker weighs, by choosing $e^{*}$, the cost of exerting effort against the benefit of being kind toward the manager.

Before we narrow the focus on the analysis of indirect reciprocity, we outline the precise structure of the game under consideration. Figure 2.2 shows its extensive form. The 'experimenter' draws first and determines the 'treatment'. There are three treatments. In the treatment OWNWAGE, the worker $W$ observes her own wage $r_{W}$ but not the coworker's wage $r_{C}$. This treatment is mainly used as a benchmark. In treatment COWORKER, $W$ observes $r_{C}$ but not $r_{W}$. In this case, $r_{C}$ may serve as a signal for $r_{W}$, i.e. $r_{W}=r_{W}^{s}\left(r_{C}\right)$. If a higher $r_{C}$ signals higher $r_{W}$, the coworker's wage increases $M$ 's kindness as perceived by $W$. In treatment $B O T H, W$ observes both wage rates. Importantly, $M$ does not know whether the treatment is OWNWAGE, COWORKER or BOTH, i.e. whether $W$ can observe $r_{W}$ or not. That is, the informational content of $r_{W}$ and $r_{C}$ does not vary across the treatments.

\footnotetext{
${ }^{18}$ Rabin (1993) proposes, again, to normalize the payoff difference:

$$
\lambda_{W}\left(r_{W}, r_{C}, e^{b}\right)=\frac{\pi_{W}\left(r_{W}, e^{b}\right)-\pi_{W}\left(\bar{r}_{W}, e^{b}\right)}{\pi_{W}\left(\bar{r}_{W}, e^{b}\right)}
$$

${ }^{19}$ Assuming $k^{\prime}(0)=0$, we have $e^{*}=0$ if $\lambda_{W}() \leq$.0 .
} 
Figure 2.2: Game tree of the experiment.

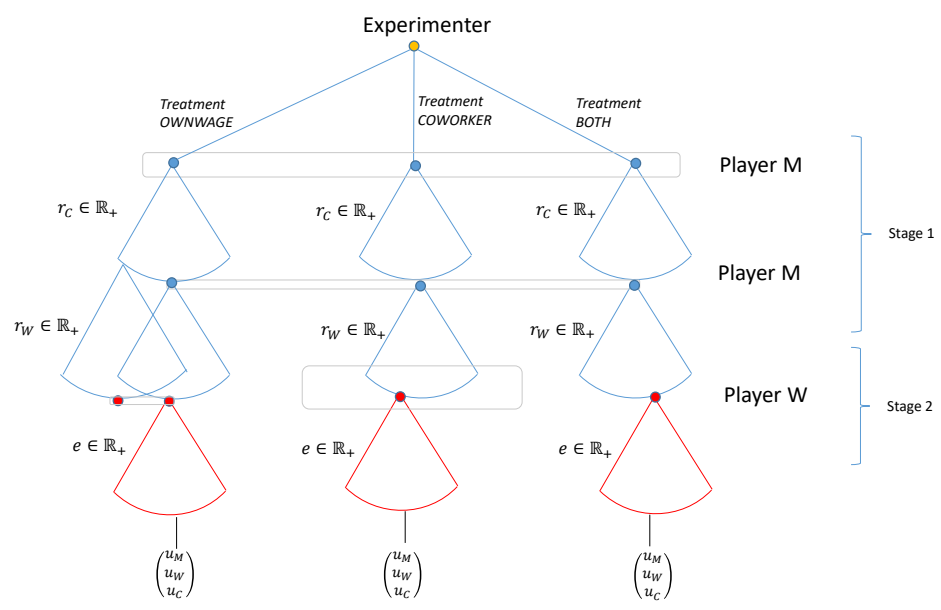

We may now derive the impact of the wage rates $r_{W}$ and $r_{C}$ on $W$ 's choice of $e$ :

$$
\frac{d e}{d r_{i}}=\frac{\frac{\partial^{2} U_{W}}{\partial e \partial d r_{i}}}{-\frac{\partial^{2} U_{W}}{\partial e^{2}}} \quad \text { with } i=W, C
$$

With the above first order condition (1) representing a maximum, we have $\frac{\partial^{2} U_{W}}{\partial e^{2}}=-k^{\prime \prime}(e)+$ $Y \lambda_{W}\left(r_{W}, r_{C}, e^{b}\right) \frac{\partial^{2} \kappa_{W}\left(e, r_{W}, r_{C}\right)}{\partial e^{2}}<0$, and $\frac{\partial^{2} U_{W}}{\partial e \partial d r_{i}}$ is given by

$$
\frac{\partial^{2} U_{W}}{\partial e \partial d r_{i}}=k^{\prime}(e)\left(\frac{\frac{\partial \lambda_{W}\left(r_{W}, r_{C}, e^{b}\right)}{\partial r_{i}}}{\lambda_{W}\left(r_{W}, r_{C}, e^{b}\right)}+\frac{\frac{\partial^{2} \kappa_{W}\left(e, r_{W}, r_{C}\right)}{\partial e \partial r_{i}}}{\frac{\partial \kappa_{W}\left(e, r_{W}, r_{C}\right)}{\partial e}}\right)
$$

With $\kappa_{W}\left(e, r_{W}, r_{C}\right)=v(e)-v(\bar{e})$ and $\lambda_{W}\left(r_{W}, r_{C}, e^{b}\right)=r_{W}-\bar{r}_{W}+\alpha\left[r_{C}-\bar{r}_{C}\right]$, we can state the following.

Observation 1 A change in $r_{W}$ affects $e$ as follows:

$$
\frac{d e}{d r_{W}}=\frac{1}{-\frac{\partial^{2} U_{W}}{\partial e^{2}}} k^{\prime}(e) \frac{1}{r_{W}-\bar{r}_{W}+\alpha\left[r_{C}-\bar{r}_{C}\right]}
$$

Observation 2 If $r_{W}$ is observable, we have

$$
\frac{d e}{d r_{C}}=\frac{1}{-\frac{\partial^{2} U_{W}}{\partial e^{2}}} k^{\prime}(e) \frac{\alpha}{r_{W}-\bar{r}_{W}+\alpha\left[r_{C}-\bar{r}_{C}\right]}
$$

i.e. the coworker's wage rate $r_{C}$ only increases effort if the altruism parameter is strictly positive, $\alpha>0$.

Now, assume that $r_{W}$ is unobservable and, thus, $r_{C}$ may be used as a signal. We have now $\lambda_{W}\left(r_{W}, r_{C}, e^{b}\right)=$ $r_{W}^{s}\left(r_{C}\right)-\bar{r}_{W}+\alpha\left[r_{C}-\bar{r}_{C}\right]$. 
Observation 3 If $r_{W}$ is not observable, we have

$$
\frac{d e}{d r_{C}}=\frac{1}{-\frac{\partial^{2} U_{W}}{\partial e^{2}}} k^{\prime}(e) \frac{\alpha+\frac{\partial r_{W}^{s}\left(r_{C}\right)}{\partial r_{C}}}{r_{W}-\bar{r}_{W}+\alpha\left[r_{C}-\bar{r}_{C}\right]}
$$

i.e. the coworker's wage rate $r_{C}$ increases effort if $\alpha+\frac{\partial r_{W}^{s}\left(r_{C}\right)}{\partial r_{C}}>0$.

The above three effects are only comparable if the beliefs $r_{W}^{s}\left(r_{C}\right)$ are correct, i.e. $r_{W}^{s}\left(r_{C}\right)=r_{W}$. If this is the case, the observations above establish that

$$
\frac{\left.\frac{d e}{d r_{C}}\right|_{r_{W} \text { observable }}}{\frac{d e}{d r_{W}}}=\alpha \text { and } \quad \frac{\left.\frac{d e}{d r_{C}}\right|_{r_{W} \text { unobservable }}}{\frac{d e}{d r_{W}}}=\alpha+\frac{\partial r_{W}^{s}\left(r_{C}\right)}{\partial r_{C}}
$$

This allows us to identify $\alpha$ and, in a second step, $\frac{\partial r_{W}^{s}\left(r_{C}\right)}{\partial r_{C}}$.

\subsection{The experiment}

At the beginning of each experimental session, each participant receives an initial endowment of 400 points $\left(25\right.$ points $=1$ Euro). The instructions ${ }^{20}$ are handed out and read aloud by the experimenter. Afterward, open questions are answered and participants have to calculate two control tasks (available upon request). Then, participants are randomly assigned to the roles of manager, worker and coworker. These roles are kept throughout the whole experiment.

The core experiment consists of 30 (or 31) periods. At the beginning of each period, all participants are randomly and anonymously matched in triples, with each role (manager, worker, coworker) represented once. The manager sets the wages and, then, the worker sets her effort level. At the end of each period, the players are informed about their payoffs.

The manager sets a wage $r_{i} \in\{0,1, \ldots, 100\}$ for each worker $i$. The worker sets an effort level $e_{i} \in$ $\{1,2, \ldots, 10\}$. Effort comes at a cost as depicted in table 2.1. ${ }^{21}$ The coworker is not able to choose effort (and, thus, to respond to wages set by the manager); her effort is fixed at $e_{C}=4 .^{22}$

Table 2.1: Cost-Effort-Function.

\begin{tabular}{l|rrrrrrrrrr}
\hline \hline Effort $e_{i}$ & 1 & 2 & 3 & 4 & 5 & 6 & 7 & 8 & 9 & 10 \\
\hline Cost of effort $k\left(e_{i}\right)$ & 0 & 2 & 4 & 8 & 12 & 16 & 20 & 24 & 30 & 36 \\
\hline \hline
\end{tabular}

Payoffs are as follows. The worker or coworker $i$ has a payoff of

$$
\pi_{i}=r_{i}-k\left(e_{i}\right)
$$

The manager has a payoff of

$$
\pi_{M}=15\left(e_{W}+e_{C}\right)-r_{W}-r_{C} .
$$

\footnotetext{
${ }^{20}$ An English translation is available upon request.

${ }^{21}$ The cost-effort function is similar to those used by e.g. Fehr et al. (1993), Fehr et al. (1998a), Gächter and Falk (2002), Maximiano et al. (2007), Rivas (2009), Siang et al. (2011), Bonein (2018), Brown et al. (2017) and Dariel and Riedl (2017).

${ }^{22}$ The coworker, however, has to state an hypothetical effort that does not affect outcomes.
} 
The effort levels $\mathbf{e}=\left(e_{W}, e_{C}\right)$ determine the size of the pie, while wages $\mathbf{r}=\left(r_{W}, w_{C}\right)$ distribute the pie between the players. The Pareto optimum is given by $\mathbf{e}=(10,10)$ with arbitrary wage levels. The subgame perfect Nash equilibrium in a one-shot game with selfish players is $\mathbf{e}=(1,1)$ and $\mathbf{r}=(0,0)$. In the first period of each session (except for the first three sessions ${ }^{23}$ ), workers are asked to use the strategy method (Selten, 1967) to indicate their effort for 21 wage levels in multiples of $5(0,5, \ldots, 100)$ before being informed about their actual wage. ${ }^{24}$

In the following 18 periods, the core experiment (the baseline) takes place. As outlined above, there are three treatments. In $O W N W A G E$, the worker only observes her own wage $r_{W}$. In COWORKER, the worker only observes the coworker's wage $r_{C}$. In $B O T H$, she observes both wages. With the altruism motive, the coworker's wage affects the worker's choice in the COWORKER and BOTH treatments. With the signaling motive, the coworker's wage is only relevant for the effort choice in the COWORKER treatment.

The BOTH, OWNWAGE and COWORKER treatments are played in a random order such that the manager is not able to differentiate treatments. This ensures that wage setting does not systematically vary across treatments. After this, treatments are slightly modified to perform some robustness checks (for another 8 to 12 periods, depending on the session) that will be explained in Sect. 4. Subsequently, all participants play a modified dictator game and an ultimatum game and fill in a questionnaire in order to elicit their other-regarding preferences. ${ }^{25}$

Finally, each participant receives the payoff (in Euro) of one randomly selected round in addition to their initial endowment.

The experimental sessions took place in January, April and June 2018 at the University of Münster. The experiment and the questionnaire were programmed in z-Tree (Fischbacher, 2007). Participants were recruited among university students using the online recruitment system ORSEE (Greiner, 2015). 234 individuals participated in 13 sessions (42.7\% female, $46.6 \%$ students of Business Administration or Economics, 23.1 average age). Each session lasted approximately 60 minutes. On average, individuals earned 17.10 Euro, with a minimum of 13.20 and a maximum of 21.40 Euro.

\section{Results}

In this section, we focus on data from the 18 periods of the baseline experiment.

\footnotetext{
${ }^{23}$ Tables C.1 and C.2 in the Appendix give an overview of the exact settings played.

${ }^{24}$ In the first four periods of session $1-3$, we conducted a standard multi-player gift-exchange game to estimate these preferences on cooperative behavior.

${ }^{25}$ The questionnaire covers personal information such as sex, age, field of study, questions on the complexity of the experiment and the participant's ability, perceptions of fairness and reciprocity, and political opinions. Questions on perceptions of reciprocity and political opinions are adopted from TNS Infratest Sozialforschung (2015).
} 


\subsection{Descriptive evidence}

We start by replicating a couple of results well-known from the literature. Figure 3.1 illustrates the evidence for the direct reciprocity pattern usually observed in gift-exchange games. Workers respond to higher wages by increasing their effort. The average effort for above median own wages (in $O W N W A G E)$ is $3.44(S D=2.55)$ compared to $1.16(S D=0.91)$ for below median wages. The average wage for the worker (in $O W N W A G E)$ is $r_{W}=26.49(S D=28.65)$, with a median of $r_{W}=20$. In COWORKER, the coworker receives only $r_{C}=13.52(S D=15.71)$ with a median of $r_{C}=10 .^{26}$ This is in line with the manager's (correct) anticipation that the coworker cannot retaliate.

Moreover, there is evidence for indirect reciprocity in the treatment COWORKER. The worker rewards the manager for being kind to the coworker. The effort level is generally (and significantly) lower in this treatment, though. The average effort $e_{W}$ for above median coworker wages is $e_{W}=2.21(S D=1.79)$ compared to $1.67(S D=1.72)$ for below median wages. ${ }^{27}$

Figure 3.1: Average worker's effort in OWNWAGE and COWORKER.

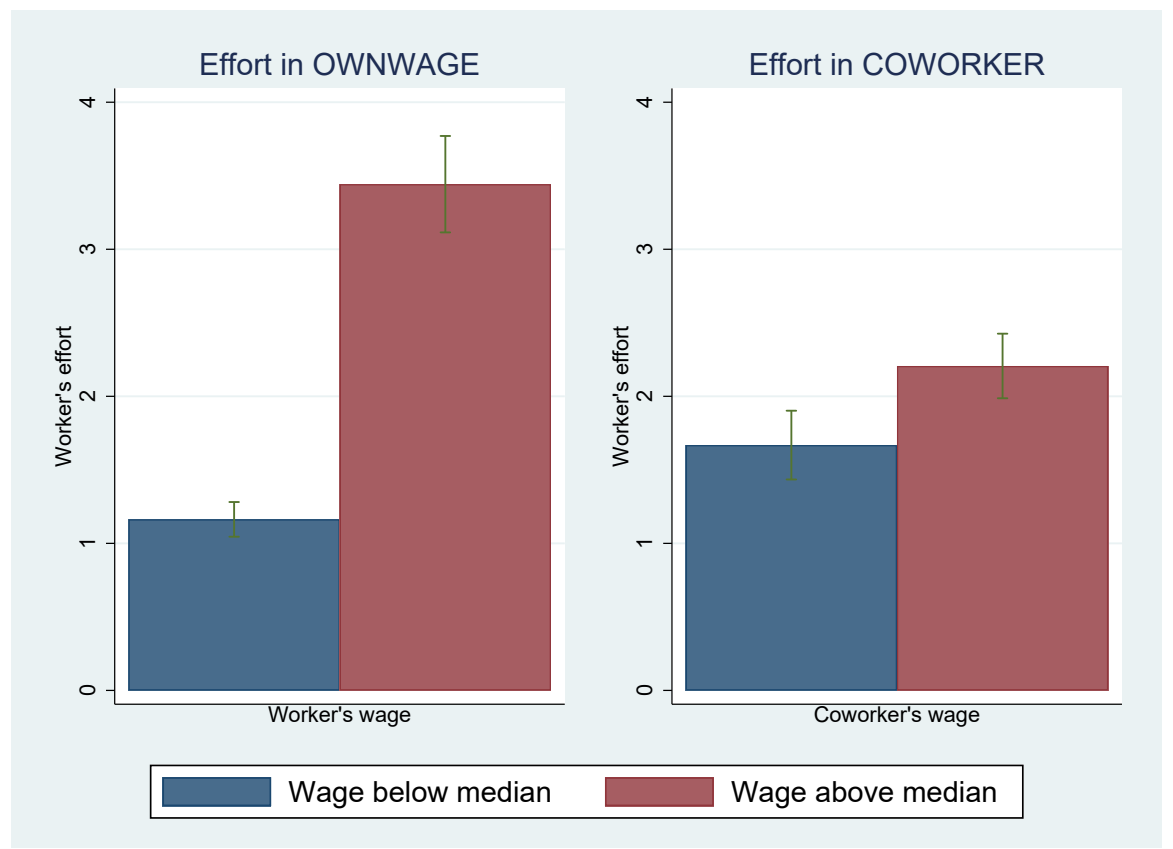

Note: The green lines depict the $95 \%$ confidence interval.

We may now analyze our main hypothesis. Is the coworker's wage $r_{C}$ merely a signal for the worker's own wage? Or does it have an impact even when the own wage is observable? Figure 3.2 suggests that $r_{C}$ is merely a signal. The figure uses observations from BOTH and controls for $r_{W}$ first. Neither for $r_{W}$ below the median wage nor for $r_{W}$ above the median wage we observe a positive response toward $r_{C}$. If at all, a higher coworker's wage seems to reduce the worker's effort.

\footnotetext{
${ }^{26} \mathrm{As}$ usual, there is substantial heterogeneity in wage setting. 3 out of 78 managers always chose the zero lower bound for the worker, $r_{W}=0.8$ managers always chose the zero lower bound for the coworker, $r_{C}=0$.

${ }^{27} 15$ workers $(19.2 \%)$ always selected the lowest possible effort of one.
} 
Figure 3.2: Average worker's effort in BOTH.

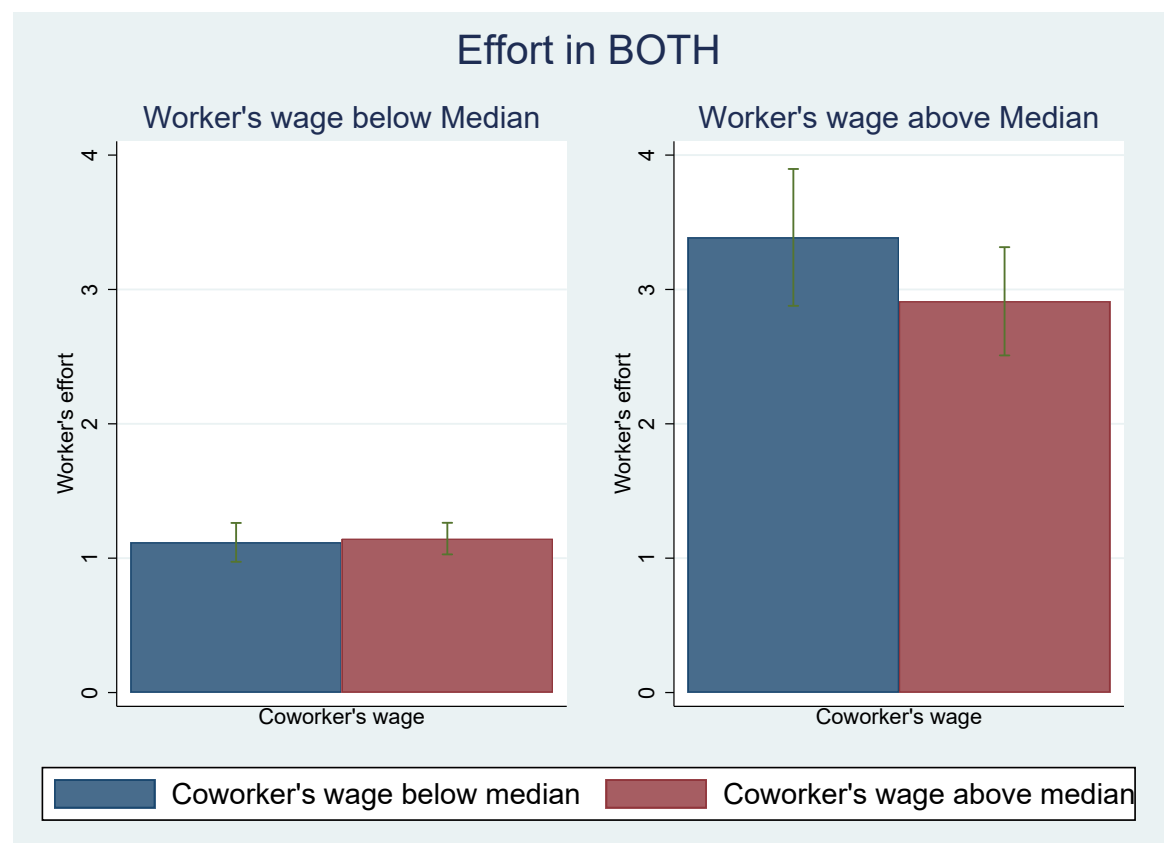

Note: The green lines depict the $95 \%$ confidence interval.

\subsection{Regression analysis}

In order to fully exploit the richness of our data, we now turn to regression analysis. The results are presented in table 3.1. We use pooled OLS with standard errors clustered at the session level as our preferred specification. Unobserved individual effects may partly explain the dependent variable $e_{W}$. However, since wages are set by the manager who neither knows the workers' characteristics nor which treatment is played, the unobserved individual effect is supposed to be unrelated to the explanatory variables $r_{W}$ and $r_{C}$. Hence, pooled OLS gives consistent estimates.

As columns (1) and (2) show, participants show directly and indirectly reciprocal behavior, depending on which wage is observable. An increase in $r_{W}$ or $r_{C}$ by 10 units implies an increase in effort by 0.48 or 0.32 , respectively. An increase of one standard deviation of the wage rate $r_{i}$ increases the effort by 1.39 and 0.50 , respectively (which corresponds to 62.13 and 27.88 percent of the standard deviation of effort). The associated elasticities, evaluated at the sample means, are $\epsilon_{r_{W}}=0.56$ and $\epsilon_{r_{C}}=0.22$. That is, an increase in the wage rate $r_{W}$ by 10 percent increases effort by 5.6 percent; an increase in $r_{C}$ by 10 percent increases effort by 2.2 percent. ${ }^{28}$ The coefficient on $r_{C}$ in COWORKER gives us the estimate for $\left.\frac{d e}{d r_{C}}\right|_{r_{W} \text { unobservable }}=0.0315$ as derived in the model, see Sect. 2.1.

\footnotetext{
${ }^{28}$ As an aside, note that, on average, the manager does not recover the additional wage cost, since $d \pi=15 \cdot d e-d r_{W}<0$ for $d r_{W}=10$ and $d e=\{0.48,0.32\}$.
} 
Table 3.1: Effect of wages on effort in baseline.

\begin{tabular}{|c|c|c|c|c|}
\hline & \multicolumn{4}{|c|}{ Dependent variable: $e_{W}$} \\
\hline & $\begin{array}{c}(1) \\
O W N W A G E\end{array}$ & $\begin{array}{c}(2) \\
\text { COWORKER }\end{array}$ & $\begin{array}{c}(3) \\
B O T H\end{array}$ & $\begin{array}{c}(4) \\
\text { OWNWAGE } \\
\text { COWORKER } \\
\text { BOTH }\end{array}$ \\
\hline$r_{W}$ & $\begin{array}{c}0.0484^{* * *} \\
(0.0070)\end{array}$ & & $\begin{array}{c}0.0496^{* * *} \\
(0.0091)\end{array}$ & $\begin{array}{c}0.0484^{* * *} \\
(0.0070)\end{array}$ \\
\hline$r_{C}$ & & $\begin{array}{c}0.0315^{* * *} \\
(0.0073)\end{array}$ & $\begin{array}{l}-0.0115 \\
(0.0087)\end{array}$ & $\begin{array}{c}0.0315^{* * *} \\
(0.0073)\end{array}$ \\
\hline $\begin{array}{l}r_{W} \\
\times B O T H\end{array}$ & & & & $\begin{array}{c}0.0012 \\
(0.0086)\end{array}$ \\
\hline $\begin{array}{l}r_{C} \\
\times B O T H\end{array}$ & & & & $\begin{array}{c}-0.0430^{* * *} \\
(0.0121)\end{array}$ \\
\hline$O W N W A G E$ & & & & $\begin{array}{l}-0.0093 \\
(0.0915)\end{array}$ \\
\hline COWORKER & & & & $\begin{array}{c}0.5017^{* * *} \\
(0.1270)\end{array}$ \\
\hline Constant & $\begin{array}{c}1.0265^{* * *} \\
(0.1012)\end{array}$ & $\begin{array}{c}1.5374^{* * *} \\
(0.1369)\end{array}$ & $\begin{array}{c}1.0357^{* * *} \\
(0.0821)\end{array}$ & $\begin{array}{c}1.0357^{* * *} \\
(0.0821)\end{array}$ \\
\hline$N$ & 468 & 468 & 468 & 1404 \\
\hline Adj. $R^{2}$ & 0.3847 & 0.0757 & 0.4053 & 0.3164 \\
\hline
\end{tabular}

Standard errors clustered at the session level.

${ }^{*} p<.1,{ }^{* *} p<.05,{ }^{* * *} p<.01$. 
Column (3) demonstrates that, if both wages are observable, only the own wage has an impact. $\frac{d e}{d r_{W}}=$ 0.0496 is highly significant, and the coefficient of the coworker's wage is negative and insignificant, i.e., $\left.\frac{d e}{d r_{C}}\right|_{r_{W} \text { observable }}$ is indistinguishable from zero. The worker does no longer reward kindness toward her coworker. This finding is in line with the idea that $r_{C}$ is just a signal for the unobservable own wage in COWORKER - and that indirect reciprocity is not rooted in altruism.

In column (4), we present estimates in a sample that pools all three treatments. The coefficient on $r_{C} \times B O T H$ is negative and significant. Hence, the effect of $r_{C}$ in BOTH is significantly lower than in COWORKER. This does not hold for the coefficient on $r_{W} \times B O T H$. The effect of $r_{W}$ is not affected by making $r_{C}$ observable as well. ${ }^{29}$

As an illustration of our regression results, the confidence intervals of the point estimates shown in table 3.1 are presented in figure 3.3. The magnitude of the effect of $r_{W}$ on $e_{W}$ changes only marginally between $O W N W A G E$ and BOTH. Standard errors and hence the confidence intervals remain roughly stable. For $r_{C}$ the effect on $e_{W}$ is smaller, even in COWORKER. The positive effect becomes negative and insignificant in BOTH. The new coefficient also does not coincide with the previous confidence interval.

Figure 3.3: Coefficients of table 3.1 with $95 \%$ confidence intervals.

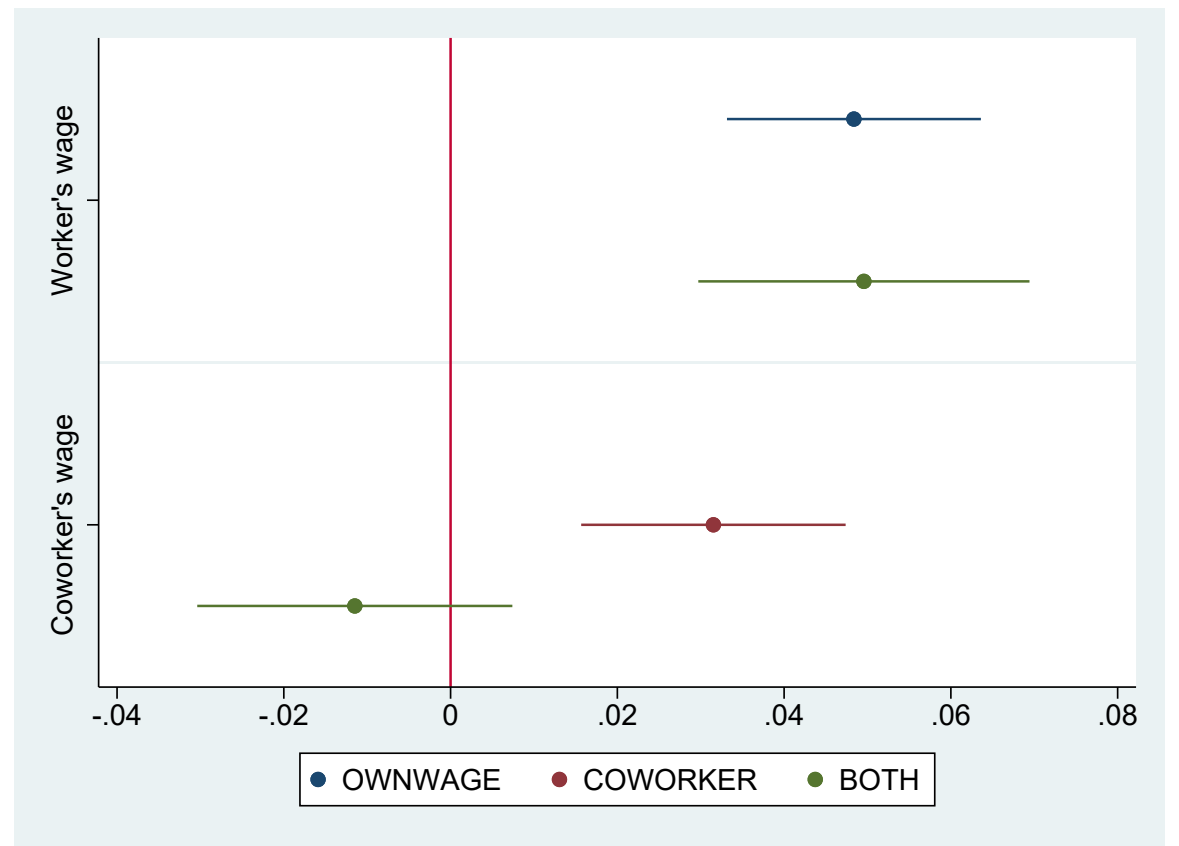

The estimated regression models are further plotted in figure 3.4. The effect of $r_{W}$ on $e_{W}$ almost coincides for $O W N W A G E$ and $B O T H$. For $r_{C}$, there is a significantly positive correlation in COWORKER and an insignificantly negative correlation in BOTH.

\footnotetext{
${ }^{29}$ As a robustness check, we further run fixed- and random effects models to obtain more efficient estimates (see table A.2 in the Appendix). Coefficients and significance levels remain stable for any of these models.
} 
The figure also suggests that for wages below 30 the worker exerts a higher effort in COWORKER than in $O W N W A G E$. For $r_{W} \leq 30$ in $O W N W A G E$, the average effort amounts to $e_{W}=1.44(S D=1.30)$, while we observe a significantly higher effort of $e_{W}=1.81(S D=1.67)$ for $r_{C} \leq 30$ in COWORKER. This might reflect the worker's correct anticipation that her own (unobservable) wage is higher than the observable $r_{C}$ in the COWORKER treatment. Regressing $r_{W}$ on $r_{C}$, see table 3.2 , shows that $r_{C}$ serves as a reasonable predictor for $r_{W}$. It is on average 15.6 units larger than $r_{C}$.

Figure 3.4: Effect of wages on worker's effort in baseline.

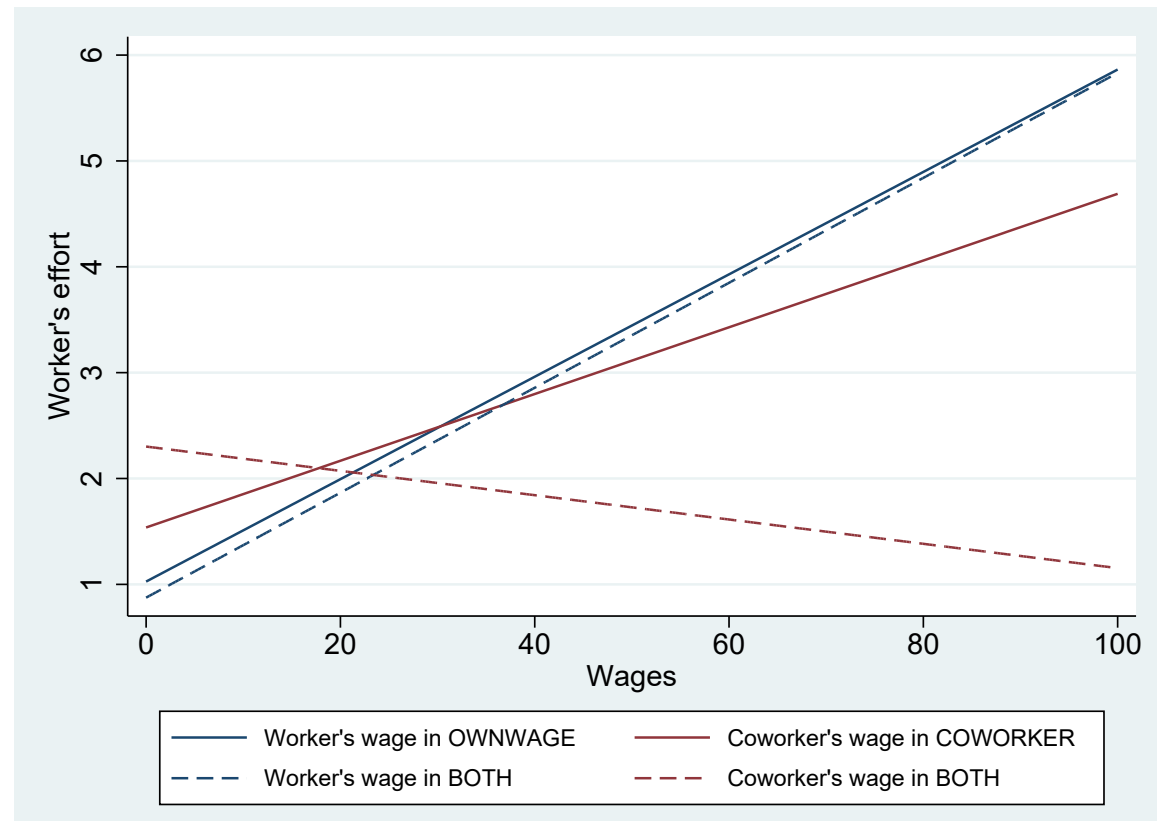

Table 3.2: Regression of $r_{W}$ on $r_{C}$ in COWORKER.

\begin{tabular}{cc}
\hline \hline & Dependent variable: $r_{W}$ \\
\hline$r_{C}$ & $0.6199^{* * *}$
\end{tabular}

\begin{tabular}{lc} 
Constant & $15.5999^{* * *}$ \\
& $(3.3569)$ \\
\hline$N$ & 468 \\
Adj. $R^{2}$ & 0.1204 \\
\hline \hline Standard errors clustered at the session level. \\
${ }^{*} p<.1,{ }^{* *} p<.05,{ }^{* * *} p<.01$.
\end{tabular}

We may now use the results to derive the structural parameters in the model in Sect. 2.1. As already pointed out, the estimate for $\alpha$ cannot be distinguished from zero. With $\alpha=0$, the point estimate for the signal is then given by 


$$
\frac{\left.\frac{d e}{d r_{C}}\right|_{r_{W} \text { unobservable }}}{\frac{d e}{d r_{W}}}=\alpha+\frac{\partial r_{W}^{s}\left(r_{C}\right)}{\partial r_{C}} \approx 0.8670
$$

This point estimate suggests that, on average, workers interpret the coworker's wage as a strong signal for their own wage. However, they expect a closer relationship between the coworker's wage and their own wage than there is (see table 3.2).

The missing response of $e_{W}$ to $r_{C}$ in BOTH may be due to heterogeneity across participants, which is typical for studies on reciprocity (see e.g. Gächter and Thöni, 2010; Toussaert, 2017). We therefore look at subsamples of participants with certain characteristics.

As a first step, we focus on those worker type individuals who respond to $r_{C}$ in COWORKER to see if they also show a non-response toward $r_{C}$ in $B O T H$. We therefore consider all workers whose correlation coefficient between $r_{C}$ and $e_{W}$ is positive in the COWORKER treatment - which is true for 38 of 78 workers. ${ }^{30}$ In table A.3 in the Appendix, we report the results of a separated analysis of these 38 participants and the non-indirect-reciprocal individuals. For none of the two groups we observe a positive effect of $r_{C}$ on $e_{W}$ in BOTH (see table A.3 in the Appendix).

In a second approach, we use the data from the strategy method applied in period 1 of sessions 4 through 13 in order to calculate the reciprocity index (RI) as suggested by Dariel and Riedl (2017). ${ }^{31}$ According to this measure, $78.3 \%$ of worker individuals behave directly reciprocally. Workers with above median $R I$ show a stronger response toward increases in their own wage than those with below median $R I$ (see table A.4 in the Appendix). However, workers with above median $R I$ do not show a larger response to the coworker's wage in the COWORKER treatment. ${ }^{32}$ For both subgroups (below and above median $R I), r_{C}$ has no effect on $e_{W}$ in $B O T H$ where both wages are observable.

As a third approach, we use the data from the modified dictator game (MDG) and the ultimatum game (UG) played at the end of the experiment. These observations allow us to calculate measures of inequality aversion (Fehr and Schmidt, 1999), as proposed by Blanco et al. (2011). Basically, the model of inequality aversion states that, apart from their own material payoff, individuals also care about the distribution of payoffs among players. More specifically, individuals derive disutility from having a lower payoff ('envy') or a higher payoff ('guilt') than others. The Appendix B.2 provides more information how we use our data to calculate the indicators for envy and guilt. We consider the impact of wages on effort $e_{W}$ for below and above median guilt-parameters and for below and above median envy-parameters. The results are presented in table A.5 and A.6 in the Appendix. For all of the four subgroups we observe a positive effect of $r_{W}$ in $O W N W A G E$ and a positive effect of $r_{C}$ in COWORKER. Coefficients on $r_{W}$ are higher for individuals above the respective median.

\footnotetext{
${ }^{30}$ Following the classification of Gächter and Thöni (2010), 29 workers in our setting can be identified as unconditional defectors, i.e. they always choose $e_{W}=1$. 11 individuals show a negative correlation of $e_{W}$ and $r_{C}$, i.e. they may be called 'envious'.

${ }^{31}$ The strategy method provides us with exactly one effort response to all possible wages. This allows calculating a Spearman's rank correlation coefficient between effort and wages for each individual. Reciprocity is defined as a significant positive correlation at the $1 \%$-level. In a second step, the index itself is calculated for reciprocal individuals to capture the magnitude of reciprocity. The calculation is explained in Appendix B.1. The index lies on the interval $R I \in[0,1] . R I=0$ stands for a completely selfish individual, who always chooses an effort of 1 irrespective of the own wage. $R I=1$ is a total altruist, who always chooses the maximum possible effort $\left(e_{W}=10\right)$.

${ }^{32}$ The coefficient of $r_{C}$ becomes even smaller for more direct reciprocal workers, with the difference being insignificant, though.
} 
The coefficient on $r_{C}$ is close to zero in $B O T H$ for all subgroups, except for workers with below median envy. These participants even seem to punish their managers for paying higher wages to the coworker (pointing to $\alpha<0$ ). ${ }^{33}$ Overall, however, we may conclude that these approaches do not yield convincing evidence for indirect reciprocity if own wages are observable.

\section{Robustness checks and extensions}

\subsection{Equalizing complexity levels}

One concern about the above results is that the treatments differ in complexity levels. Specifically, we compare the COWORKER treatment where one wage rate is displayed with the BOTH treatment with two wage rates. Due to e.g. attention constraints, participants may find it difficult to cope with two pieces of information and, therefore, opt to focus on just one wage rate: their own.

In order to rule out that attention constraints and other complexity related issues drive our findings, we consider the following robustness check (applied in sessions 4 through 13). We let the computer randomly determine $r_{W} \in\{10,40,60\} .{ }^{34}$ The manager is informed about the computer's choice $r_{W}$ and the treatment (OWNWAGE or BOTH) before she chooses $r_{C}$. OWNWAGE and BOTH are played with certainty for 6 periods each. We label this treatment 'exo' ${ }^{35}$

Column (1) in table 4.1 shows that, with exogenous $r_{W}$, the worker still reacts positively to her wage when only her own (computer-set) wage can be observed. This finding may be interpreted as reflecting outcome-based reciprocity, since the worker cannot deduce the manager's intentional kindness from the computer-set wage rate. The coefficient is smaller than in $O W N W A G E$ with endogenous wages (see column (1) of table 3.1) and of similar magnitude as the coefficient on $r_{C}$ in COWORKER (see column $(2)$ of table 3.1$)$.

In the BOTH treatment with exogenous wages, the effect of $r_{W}$ drops further compared to the regular $O W N W A G E$ setting. At the same time, $r_{C}$ positively affects effort (and significantly so when using Random or Individual Fixed Effects, see table A.7 in the Appendix). Hence, when $r_{C}$ becomes observable, the worker seems to shift her attention from $r_{W}$ toward $r_{C}$ to assess the manager's kindness. ${ }^{36}$ Column (3) reports the effects of both wages on effort between exo and baseline. ${ }^{37} r_{W}$ has a significantly larger effect on effort in baseline; the effect of $r_{C}$ is significantly smaller in baseline. The treatment suggests that workers do not neglect $r_{C}$ in BOTH in baseline solely due to attention constraints, as both wages become significant if $r_{W}$ is set exogenously (see column (2) and (4) in table A.7 in the Appendix).

\footnotetext{
${ }^{33}$ This seems to be counterintuitive. It is in line, though, with Blanco et al. (2011) who also note that the envy-guilt model has limited predictive power at the individual level.

${ }^{34}$ These values are the 25 th-, 50 th- and 75 th percentiles of the wage rates set by the manager in sessions $1-3$.

${ }^{35}$ The changes in the experimental setting were explained in the instructions at the beginning of the experiment with a reminder just before the treatment under consideration.

${ }^{36}$ Again, the correlation between $r_{W}$ and $r_{C}$ in this setting is neglectable $\left(\operatorname{corr}\left(r_{W}, r_{C}\right)=0.0658\right)$, which is also stressed by figure A.1 in the Appendix. Even though the manager knows $r_{W}$ before setting $r_{C}$, this does not significantly affect her decision about $r_{C}$. Hence, our standard errors in this setting do not become inflated due to multicollinearity.

${ }^{37}$ In table A.9 in the Appendix, we also compare this setting to the setting with endogenous wages described in Sect. 4.2 .
} 
Table 4.1: Effect of setting $r_{W}$ exogenously in $O W N W A G E$ and BOTH.

\begin{tabular}{|c|c|c|c|}
\hline & \multicolumn{3}{|c|}{ Dependent variable: $e_{W}$} \\
\hline & $\begin{array}{c}(1) \\
O W N W A G E \\
\text { - exo }\end{array}$ & $\begin{array}{c}(2) \\
B O T H \\
\text {-exo }\end{array}$ & $\begin{array}{c}(3) \\
\text { BOTH } \\
\text {-baseline } \\
\text { E-exo }\end{array}$ \\
\hline$r_{W}$ & $\begin{array}{c}0.0360^{* * *} \\
(0.0050)\end{array}$ & $\begin{array}{c}0.0259^{* * *} \\
(0.0041)\end{array}$ & $\begin{array}{c}0.0259^{* * *} \\
(0.0040)\end{array}$ \\
\hline$r_{C}$ & & $\begin{array}{c}0.0144 \\
(0.0085)\end{array}$ & $\begin{array}{c}0.0144 \\
(0.0084)\end{array}$ \\
\hline $\begin{array}{l}r_{W} \\
\times \text { baseline }\end{array}$ & & & $\begin{array}{c}0.0237^{* *} \\
(0.0101)\end{array}$ \\
\hline $\begin{array}{l}r_{C} \\
\times \text { baseline }\end{array}$ & & & $\begin{array}{c}-0.0259^{* *} \\
(0.0105)\end{array}$ \\
\hline baseline & & & $\begin{array}{c}0.3179 \\
(0.1848)\end{array}$ \\
\hline Constant & $\begin{array}{c}0.9261^{* * *} \\
(0.1167)\end{array}$ & $\begin{array}{c}0.7179^{* * *} \\
(0.1892)\end{array}$ & $\begin{array}{c}0.7179^{\text {*** }} \\
(0.1869)\end{array}$ \\
\hline$N$ & 360 & 360 & 828 \\
\hline Adj. $R^{2}$ & 0.1323 & 0.1247 & 0.3123 \\
\hline
\end{tabular}

Standard errors clustered at the session level.

${ }^{*} p<.1,{ }^{* *} p<.05,{ }^{* * *} p<.01$.

Note: Column (1) and (2) use observations from the treatments where $O W N W A G E$ and BOTH are played with certainty and $r_{W}$ is randomly chosen by a computer. Column (3) compares the results of column (2) with BOTH in baseline. 


\subsection{Wage setting}

In the last eight periods of session 1-3, we test for the managers' expectations on the workers' reciprocal behavior. We let the participants play the regular $O W N W A G E$ and BOTH treatment with certainty. When $O W N W A G E$ is played with certainty, there is no incentive to set $r_{C}$ above a minimum threshold that the manager deems appropriate, since $r_{C}$ is not revealed to the worker. Hence, if $r_{C}$ is higher in the COWORKER treatment, the manager must believe that $r_{C}$ somehow affects $e_{W}$ - as a signal for $r_{W}$ or because the worker cares for the coworker's payoff. When BOTH is played with certainty, the worker knows her own wage and, thus, $r_{C}$ is irrelevant if its only role is to serve as a signal.

The average wages of session 1-3 are depicted in figure 4.1. In periods 5 through 22, OWNWAGE, COWORKER and BOTH are played in random order (baseline). In periods 23 through 26, OWN$W A G E$ is played with certainty as well as $B O T H$ in periods 27 through 30 . The increase in $r_{W}$ from period 22 to 23 may indicate that managers adjust their wage setting to the increased probability that the worker observes her own wage (the probability increases from $2 / 3$ to 1 ).

Similarly, $r_{C}$ is significantly higher in BOTH $\left(r_{C}=14.90, S D=15.14\right)$ than in $O W N W A G E\left(r_{C}=\right.$ $10.11, S D=12.28)$. The increase indicates that managers expect the worker to react positively to their coworker's wage in BOTH. Thus, it seems that managers do not expect $r_{C}$ to serve solely as a signal of $r_{W}$ - although the above discussed data on the worker's behavior suggests it does. Managers seem to expect that the workers' indirect reciprocity is (partly) motivated by altruistic preferences.

Figure 4.1: Average wages in session 1-3.

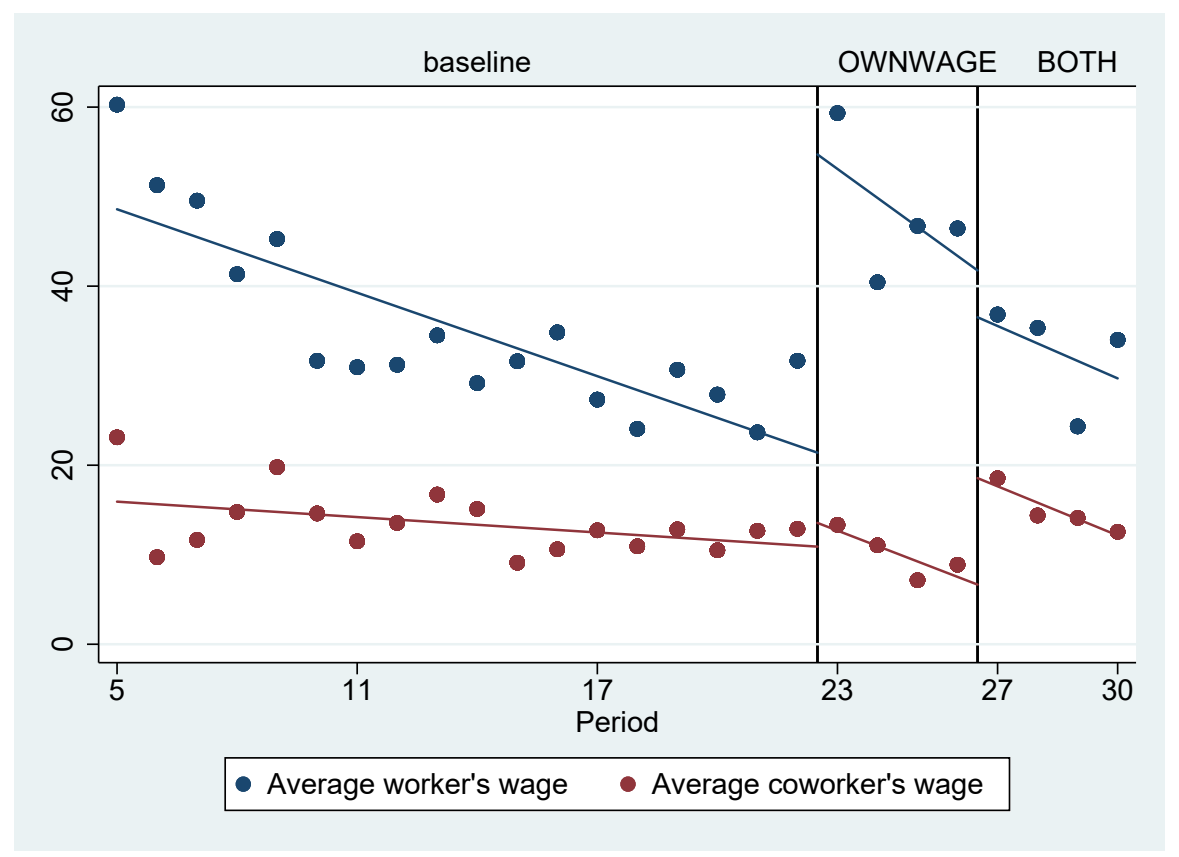




\section{Conclusion}

This paper offers a theoretical framework that defines two potential motivations of indirect reciprocity: the altruism motive and the signaling motive. It presents evidence from a lab experiment that is designed to disentangle these two kinds of motivation. We find strong support for the signaling motive in the experiment. Participants exhibit indirect reciprocity only when they have no information about the manager's kindness toward themselves. If, however, direct interaction takes place, the manager's behavior toward the coworker becomes irrelevant. These findings suggest that participants take their coworker's wage as a signal of their own wage.

Our paper, therefore, helps to explain why there is robust evidence for indirect reciprocity in e.g. helping games, but mixed to little evidence for it in gift-exchange games. Indirect reciprocity vanishes as soon as the interaction allows for direct reciprocity. 


\section{References}

Abeler, J., Altmann, S., Kube, S., and Wibral, M. (2010). Gift Exchange and Workers' Fairness Concerns: When Equality Is Unfair. Journal of the European Economic Association, 8(6):12991324.

Akerlof, G. A. (1982). Labor Contracts as Partial Gift Exchange. The Quarterly Journal of Economics, 97(4):543-569.

Akerlof, G. A. and Yellen, J. L. (1990). The Fair Wage-Effort Hypothesis and Unemployment. The Quarterly Journal of Economics, 105(2):255-283.

Alexander, R. D. (1987). The biology of moral systems. Foundations of human behavior. Aldine de Gruyter, New York.

Axelrod, R. and Hamilton, W. D. (1981). The Evolution of Cooperation. Science, 211:1390-1396.

Barta, Z. (2016). Individual variation behind the evolution of cooperation. Philosophical Transactions Royal Society B, 371(20150087):1-8.

Barta, Z., McNamara, J. M., Huszár, D. B., and Taborsky, M. (2011). Cooperation among non-relatives evolves by state-dependent generalized reciprocity. Proceedings. Biological sciences, 278(1707):843848.

Bellemare, C. and Shearer, B. (2009). Gift giving and worker productivity: Evidence from a firm-level experiment. Games and Economic Behavior, 67(1):233-244.

Berger, U. and Grüne, A. (2016). On the stability of cooperation under indirect reciprocity with first order information. Games and Economic Behavior, 98:19-33.

Blanco, M., Engelmann, D., and Normann, H. T. (2011). A within-subject analysis of other-regarding preferences. Games and Economic Behavior, 72(2):321-338.

Bolton, G. and Werner, P. (2016). The influence of potential on wages and effort. Experimental Economics, 19(3):535-561.

Bolton, G. E. and Ockenfels, A. (2000). ERC: A Theory of Equity, Reciprocity, and Competition. The American Economic Review, 90(1):166-193.

Bonein, A. (2018). Peer pressure and social comparisons with heterogeneous ability. Managerial and Decision Economics, 39:142-157.

Bowles, S. and Gintis, H. (2004). The evolution of strong reciprocity: Cooperation in heterogeneous populations. Theoretical Population Biology, 65(1):17-28.

Boyd, R. and Richerson, P. J. (1989). The evolution of indirect reciprocity. Social Networks, 11(3):213236. 
Brown, C., Evans, J., Moser, D. V., and Presslee, A. (2017). How Does Reducing Pay Dispersion Affect Employee Behavior? AAA 2017 Management Accounting Section (MAS) Meeting; 2017 Canadian Academic Accounting Association (CAAA) Annual Conference.

Charness, G. and Haruvy, E. (2002). Altruism, equity, and reciprocity in a gift-exchange experiment: an encompassing approach. Games and Economic Behavior, 40(2):203-231.

Charness, G. and Levine, D. I. (2007). Intention and Stochastic Outcomes: An Experimental study. The Economic Journal, 117(522):1051-1072.

Charness, G. and Rabin, M. (2002). Understanding Social Preferences with Simple Tests. The Quarterly Journal of Economics, 117(3):817-869.

Cohn, A., Fehr, E., Herrmann, B., and Schneider, F. (2014). Social Comparison and Effort Provision: Evidence from a Field Experiment. Journal of the European Economic Association, 12(4):877-898.

Cox, J. C. and Deck, C. A. (2005). On the Nature of Reciprocal Motives. Economic Inquiry, 43(3):623635 .

Cox, J. C., Friedman, D., and Gjerstad, S. (2007). A tractable model of reciprocity and fairness. Games and Economic Behavior, 59(1):17-45.

Dariel, A. and Riedl, A. (2017). Reciprocal Preferences and Gift-Exchange. Working Paper.

Diekmann, A. (2004). The Power of Reciprocity: Fairness, Reciprocity, and Stakes in Variants of the Dictator Game. The Journal of Conflict Resolution, 48(4):487-505.

Dufwenberg, M. and Kirchsteiger, G. (2000). Reciprocity and wage undercutting. European Economic Review, 44(4):1069-1078.

Dufwenberg, M. and Kirchsteiger, G. (2004). A theory of sequential reciprocity. Games and Economic Behavior, 47(2):268-298.

Dufwenberg, M. and Kirchsteiger, G. (2019). Modelling kindness. Journal of Economic Behavior \& Organization, 167:228-234.

Engelmann, D. and Fischbacher, U. (2009). Indirect reciprocity and strategic reputation building in an experimental helping game. Games and Economic Behavior, 67(2):399-407.

Enke, B. (2019). Kinship, Cooperation, and the Evolution of Moral Systems. The Quarterly Journal of Economics, 134(2):953-1019.

Falk, A., Fehr, E., and Fischbacher, U. (2008). Testing theories of fairness-Intentions matter. Games and Economic Behavior, 62(1):287-303.

Falk, A. and Fischbacher, U. (2006). A theory of reciprocity. Games and Economic Behavior, $54(2): 293-315$.

Fehr, E. and Gächter, S. (2000). Fairness and Retaliation: The Economics of Reciprocity. Journal of Economic Perspectives, 14(3):159-182. 
Fehr, E., Gächter, S., and Kirchsteiger, G. (1997). Reciprocity as a Contract Enforcement Device: Experimental Evidence. Econometrica, 65(4):833-860.

Fehr, E., Kirchler, E., Weichbold, A., and Gächter, S. (1998a). When Social Norms Overpower Competition: Gift Exchange in Experimental Labor Markets. Journal of Labor Economics, 16(2):324-351.

Fehr, E., Kirchsteiger, G., and Riedl, A. (1993). Does Fairness Prevent Market Clearing? An Experimental Investigation. The Quarterly Journal of Economics, 108(2):437-459.

Fehr, E., Kirchsteiger, G., and Riedl, A. (1998b). Gift exchange and reciprocity in competitive experimental markets. European Economic Review, 42(1):1-34.

Fehr, E. and Schmidt, K. M. (1999). A Theory of Fairness, Competition, and Cooperation. The Quarterly Journal of Economics, 114(3):817-868.

Fischbacher, U. (2007). z-Tree: Zurich toolbox for ready-made economic experiments. Experimental Economics, 10(2):171-178.

Fishmann, M. A., Lotem, A., and Stone, L. (2001). Heterogeneity Stabilizes Reciprocal Altruism Interactions. Journal of Theoretical Biology, 209(1):87-95.

Gächter, S. and Falk, A. (2002). Reputation and Reciprocity: Consequences for the Labour Relation. Scandinavian Journal of Economics, 104(1):1-26.

Gächter, S., Nosenzo, D., and Sefton, M. (2012). The Impact of Social Comparisons on Reciprocity. Scandinavian Journal of Economics, 114(4):1346-1367.

Gächter, S., Nosenzo, D., and Sefton, M. (2013). Peer Effects in Pro-Social Behavior: Social Norms or Social Preferences? Journal of the European Economic Association, 11(3):548-573.

Gächter, S. and Thöni, C. (2010). Social comparison and performance: Experimental evidence on the fair wage effort hypothesis. Journal of Economic Behavior \& Organization, 76(3):531-543.

Geanakoplos, J., Pearce, D., and Stacchetti, E. (1989). Psychological games and sequential rationality. Games and Economic Behavior, 1(1):60-79.

Gneezy, U. and List, J. A. (2006). Putting Behavioral Economics to Work: Testing for Gift Exchange in Labor Markets Using Field Experiments. Econometrica, 74(5):1365-1384.

Greiner, B. (2015). Subject pool recruitment procedures: Organizing experiments with ORSEE. Journal of the Economic Science Association, 1(1):114-125.

Greiner, B. and Levati, M. V. (2005). Indirect reciprocity in cyclical networks: An experimental study. Journal of Economic Psychology, 26(5):711-731.

Gross, T., Guo, C., and Charness, G. (2015). Merit pay and wage compression with productivity differences and uncertainty. Journal of Economic Behavior $\& 3$ Organization, 117:233-247.

Güth, W. (1995). An evolutionary approach to explaining cooperative behavior by reciprocal incentives. International Journal of Game Theory, 24(4):323-344. 
Heinz, M., Jeworrek, S., Mertins, V., Schumacher, H., and Sutter, M. (2017). Measuring Indirect Effects of Unfair Employer Behavior on Worker Productivity A Field Experiment. MPI Collective Goods Preprint, 22.

Herne, K., Lappalainen, O., and Kestilä-Kekkonen, E. (2013). Experimental comparison of direct, general, and indirect reciprocity. The Journal of Socio-Economics, 45:38-46.

Ito, T., Suzuki, R., and Arita, T. (2019). Evolution of four forms of reciprocity in the prisoner's dilemma game. Artificial Life and Robotics, 24(2):140-146.

Kube, S., Maréchal, M. A., and Puppe, C. (2012). The Currency of Reciprocity: Gift Exchange in the Workplace. The American Economic Review, 102(4):1644-1662.

Leimar, O. and Hammerstein, P. (2001). Evolution of cooperation through indirect reciprocity. Procedures of the Royal Society London, 268(1468):745-753.

Levine, D. K. (1998). Modeling Altruism and Spitefulness in Experiments. Review of Economic Dynamics, 1(3):593-622.

Lotem, A., Fishmann, M. A., and Stone, L. (1999). Evolution of cooperation between individuals. Nature, 400(6741):226-227.

Maximiano, S., Sloof, R., and Sonnemans, J. (2007). Gift Exchange in a Multi-Worker Firm. The Economic Journal, 117(522):1025-1050.

Moreno-Okuno, A. T. and Mosiño, A. (2017). A theory of sequential group reciprocity. Latin American Economic Review, 26(1).

Nowak, M. A. and Sigmund, K. (1998). The dynamics of indirect reciprocity. Journal of Theoretical Biology, 194(4):561-574.

Nowak, M. A. and Sigmund, K. (2005). Evolution of indirect reciprocity. Nature, 437(7063):1291-1298.

Rabin, M. (1993). Incorporating fairness into game theory and economics. American Economic Review, 83(5):1281-1302.

Reuben, E. and Riedl, A. (2013). Enforcement of contribution norms in public good games with heterogeneous populations. Games and Economic Behavior, 77(1):122-137.

Rivas, M. F. (2009). Wage dispersion and workers' effort. Economics Bulletin, 29(2):788-794.

Seinen, I. and Schram, A. (2006). Social status and group norms: Indirect reciprocity in a repeated helping experiment. European Economic Review, 50:581-602.

Selten, R. (1967). Die Strategiemethode zur Erforschung des eingeschränkt rationalen Verhaltens im Rahmen eines Oligopolexperimentes. Beiträge zur experimentellen Wirtschaftsforschung. - Tübingen : Mohr. - (1967), p. 136-168.

Sethi, R. and Somanathan, E. (2001). Preference Evolution and Reciprocity. Journal of Economic Theory, 97(2):273-297. 
Siang, C. K., Requate, T., and Waichman, I. (2011). On the role of social wage comparisons in gift-exchange experiments. Economics Letters, 112(1):75-78.

Tanaka, H., Ohtsuki, H., and Ohtsubo, Y. (2016). The price of being seen to be just: An intention signalling strategy for indirect reciprocity. Proceedings of the Royal Society B: Biological Sciences, 283(1835).

TNS Infratest Sozialforschung (2015). SOEP 2015 - Erhebungsinstrumente 2015 (Welle 32) des Soziooekonomischen Panels: Personenfragebogen, Altstichproben.

Toussaert, S. (2017). Intention-based reciprocity and signaling of intentions. Journal of Economic Behavior $\& 3$ Organization, 137:132-144.

Wedekind, C. and Milinski, M. (2000). Cooperation Through Image Scoring in Humans. Science, 288(5467):850-852. 


\section{Appendix}

\section{A Results}

\section{A.1 Statistics}

Table A.1: Median wages in baseline.

\begin{tabular}{c||c||c|c|c|c}
\hline \hline \multirow{2}{*}{ OWNWAGE } & COWORKER & \multicolumn{3}{|c}{ BOTH } \\
\hline \multirow{2}{*}{$r_{W}=20$} & \multirow{3}{*}{$r_{C}=10$} & For $r_{W}<20:$ & For $r_{W} \geq 20:$ & For $r_{C}<10:$ & For $r_{C} \geq 10:$ \\
& & $r_{C}=0$ & $r_{C}=20$ & $r_{W}=0$ & $r_{W}=30$ \\
\hline \hline
\end{tabular}

\section{A.2 Robustness checks baseline}

Figure A.1: Distribution of $r_{C}$ in exo for different values of $r_{W}$.
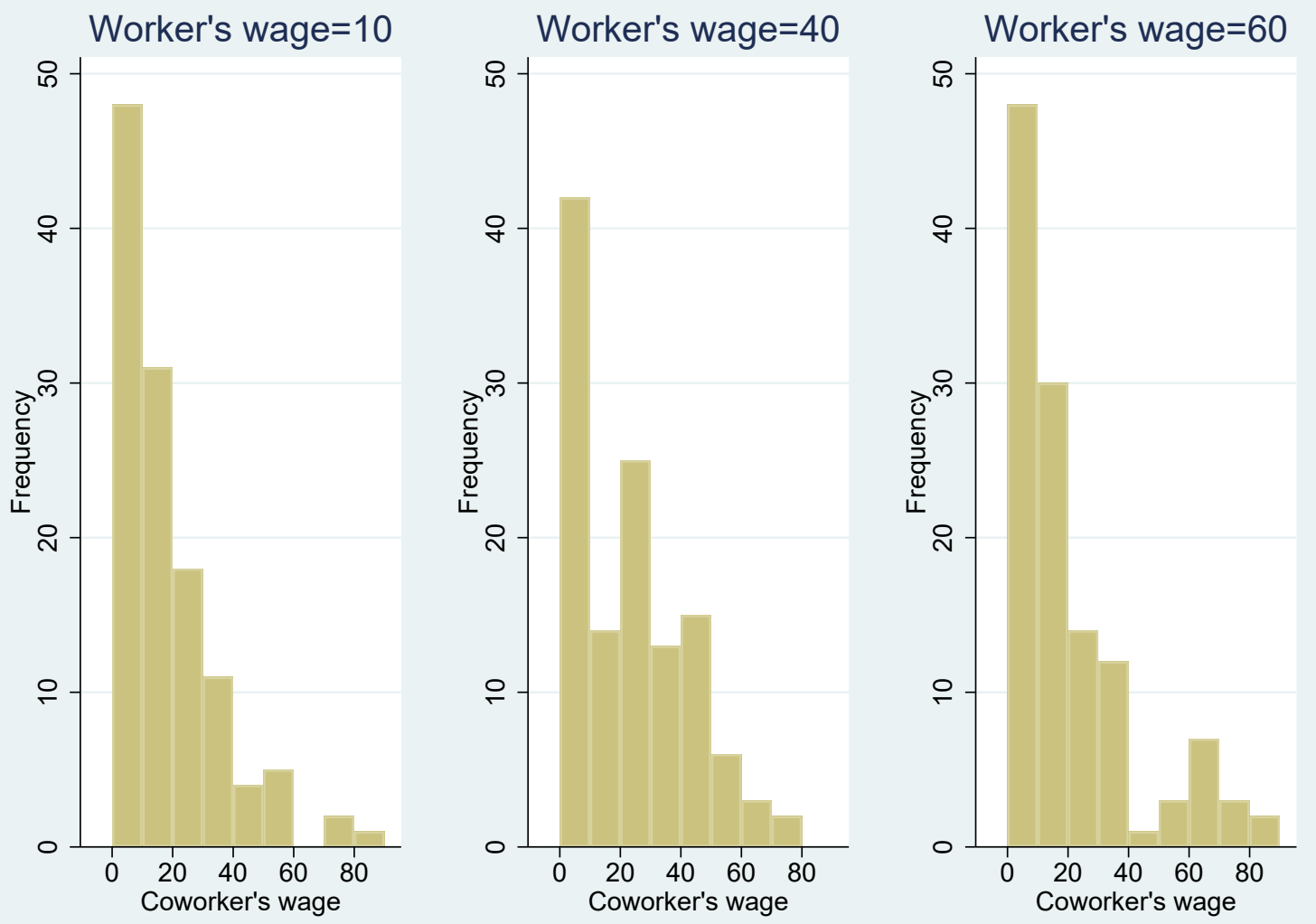


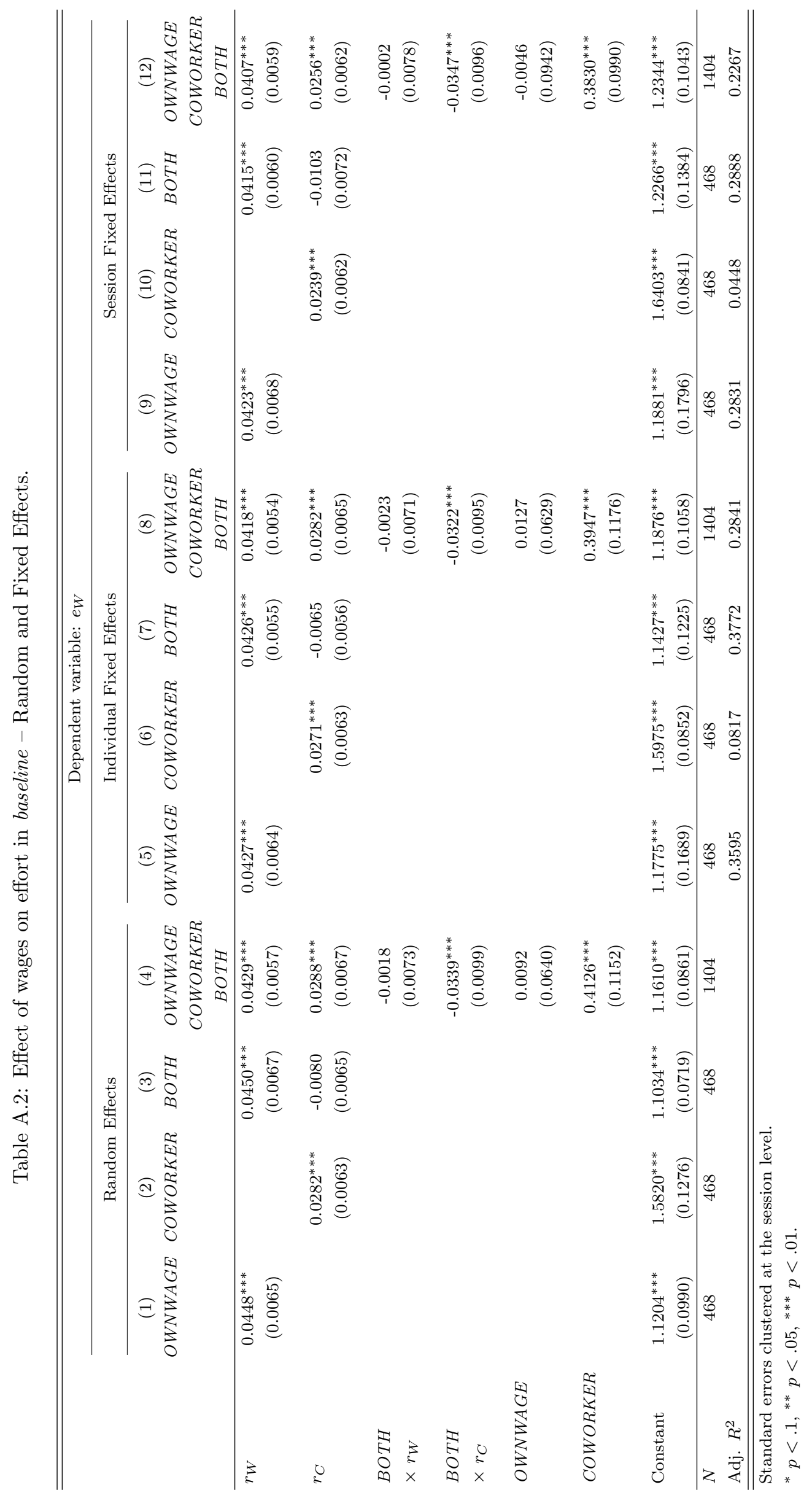




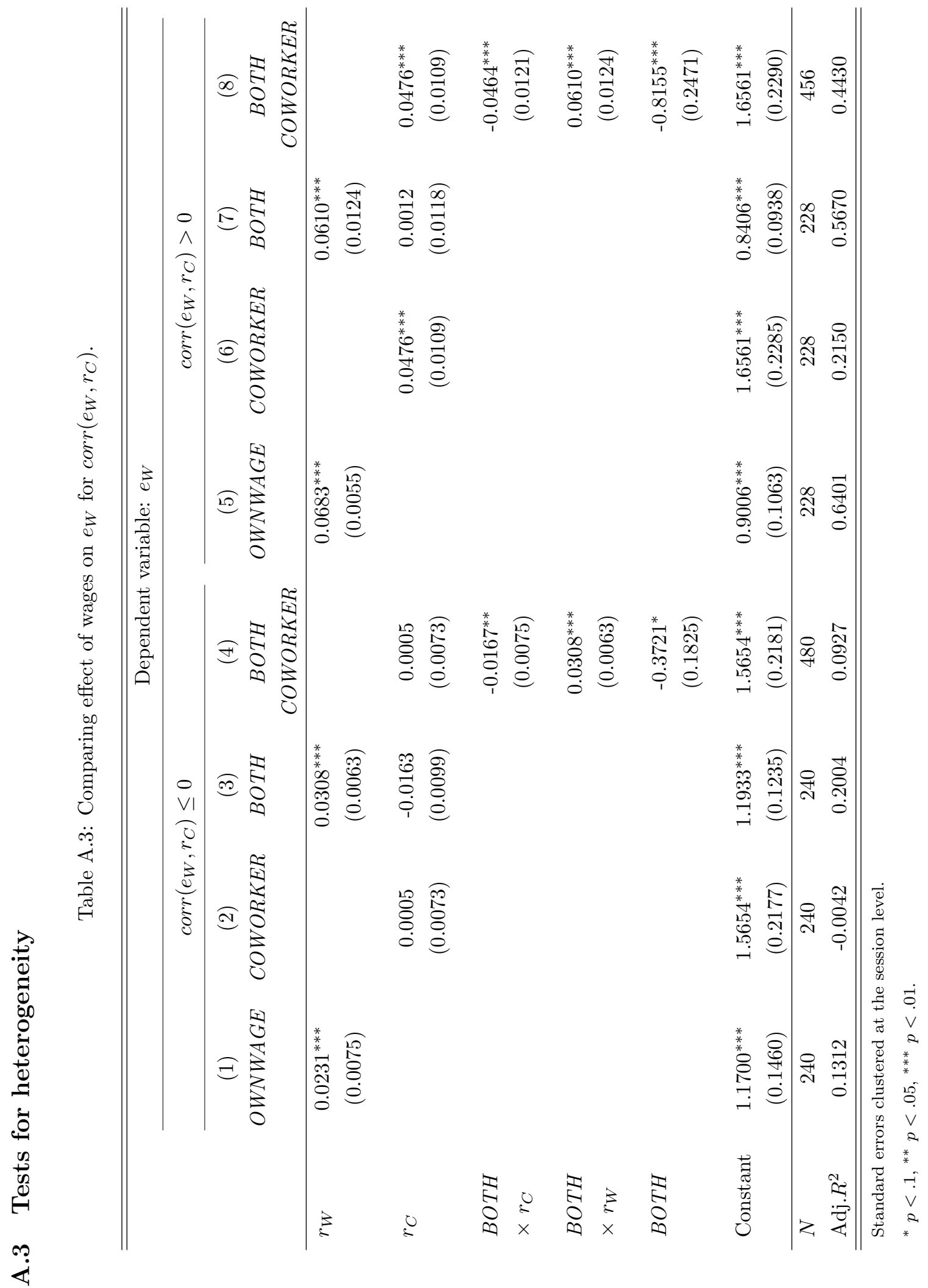




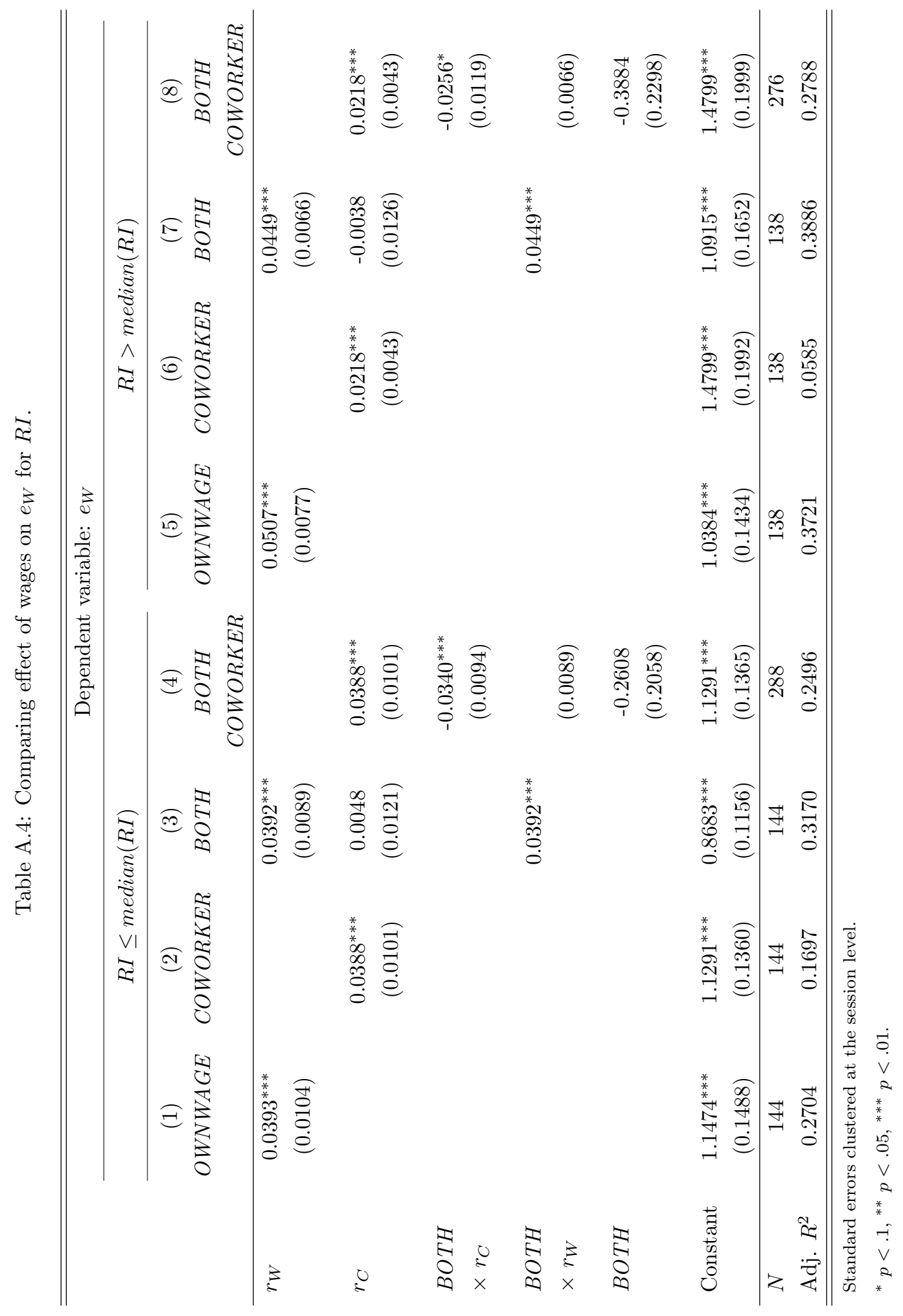




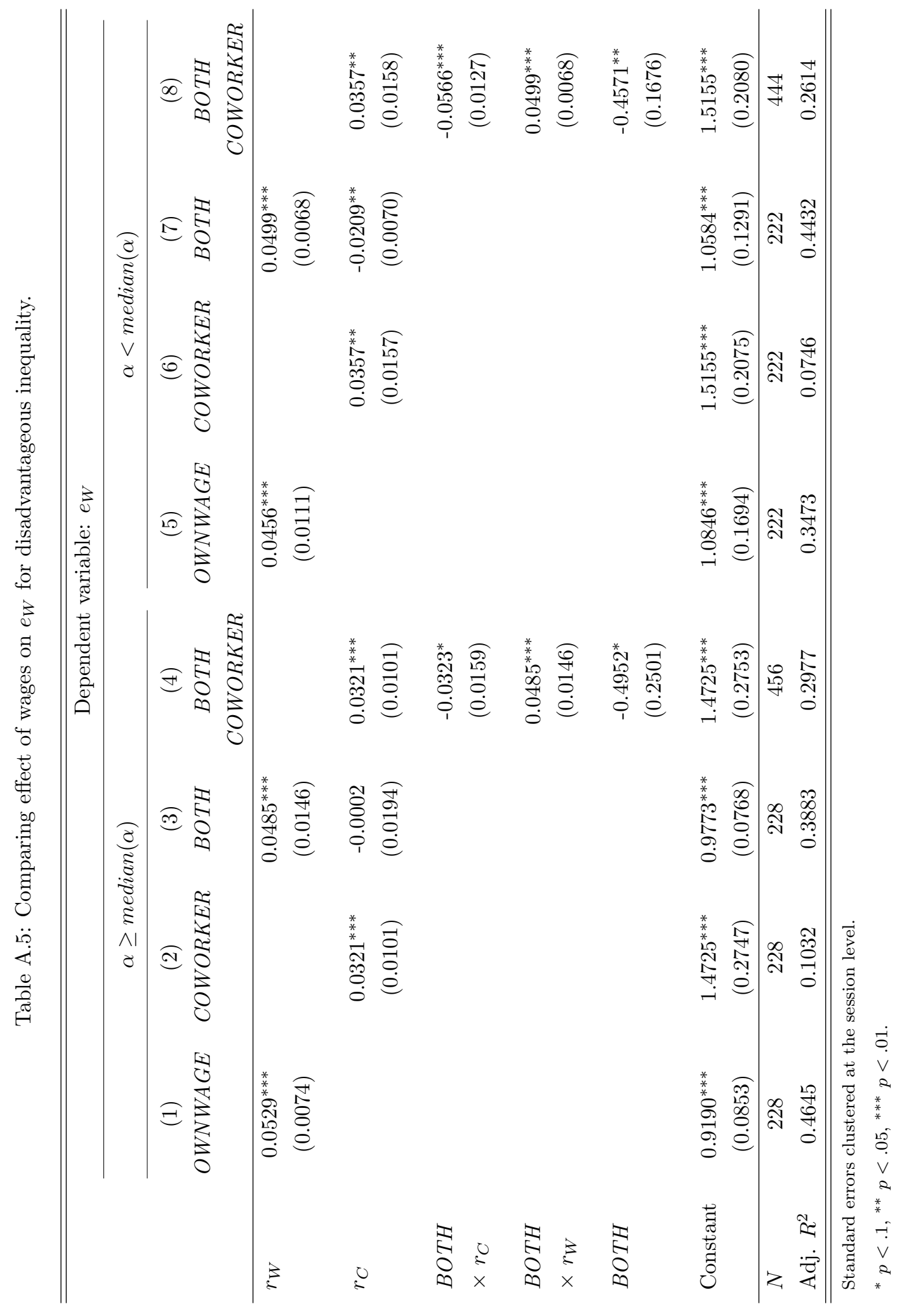




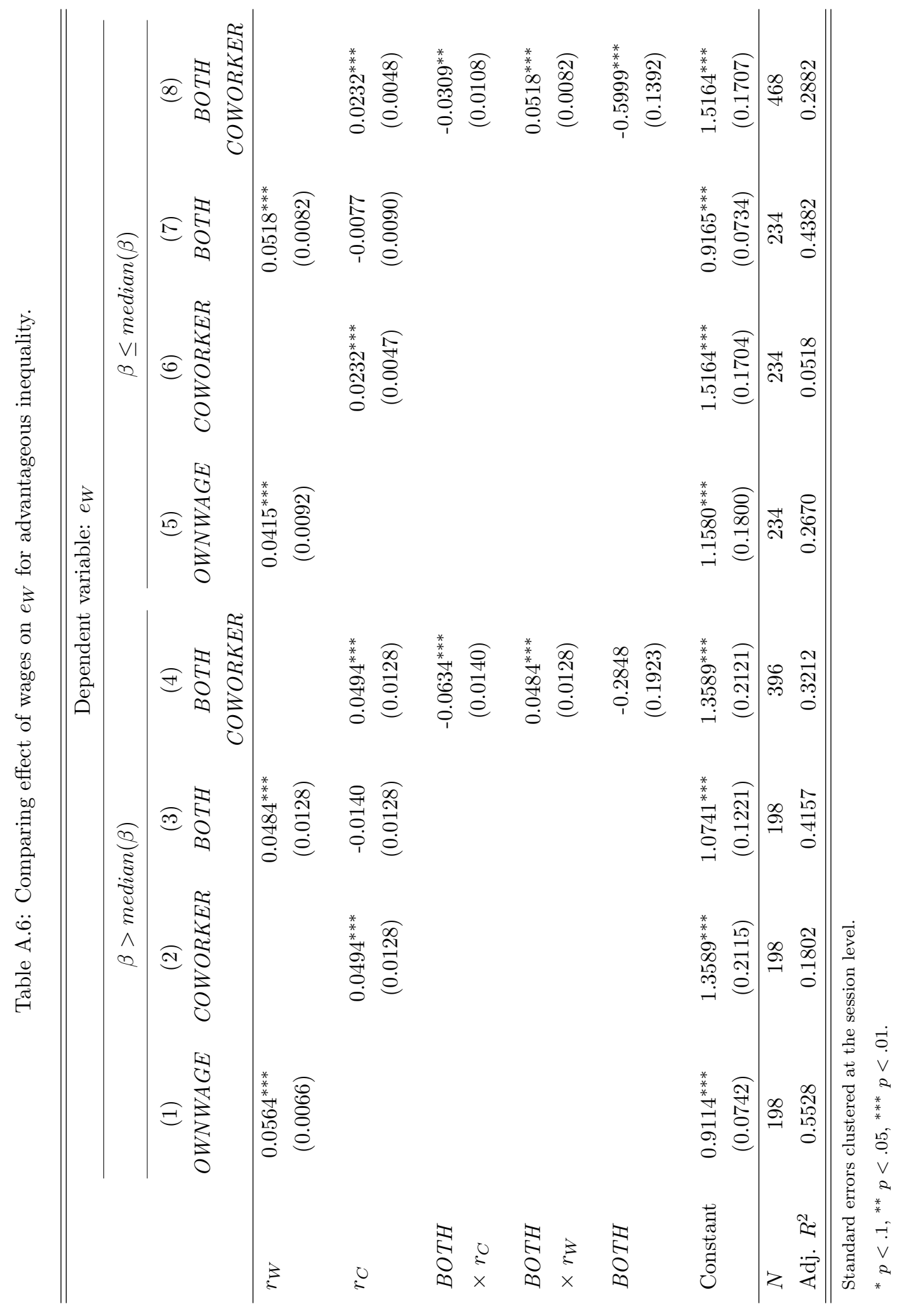




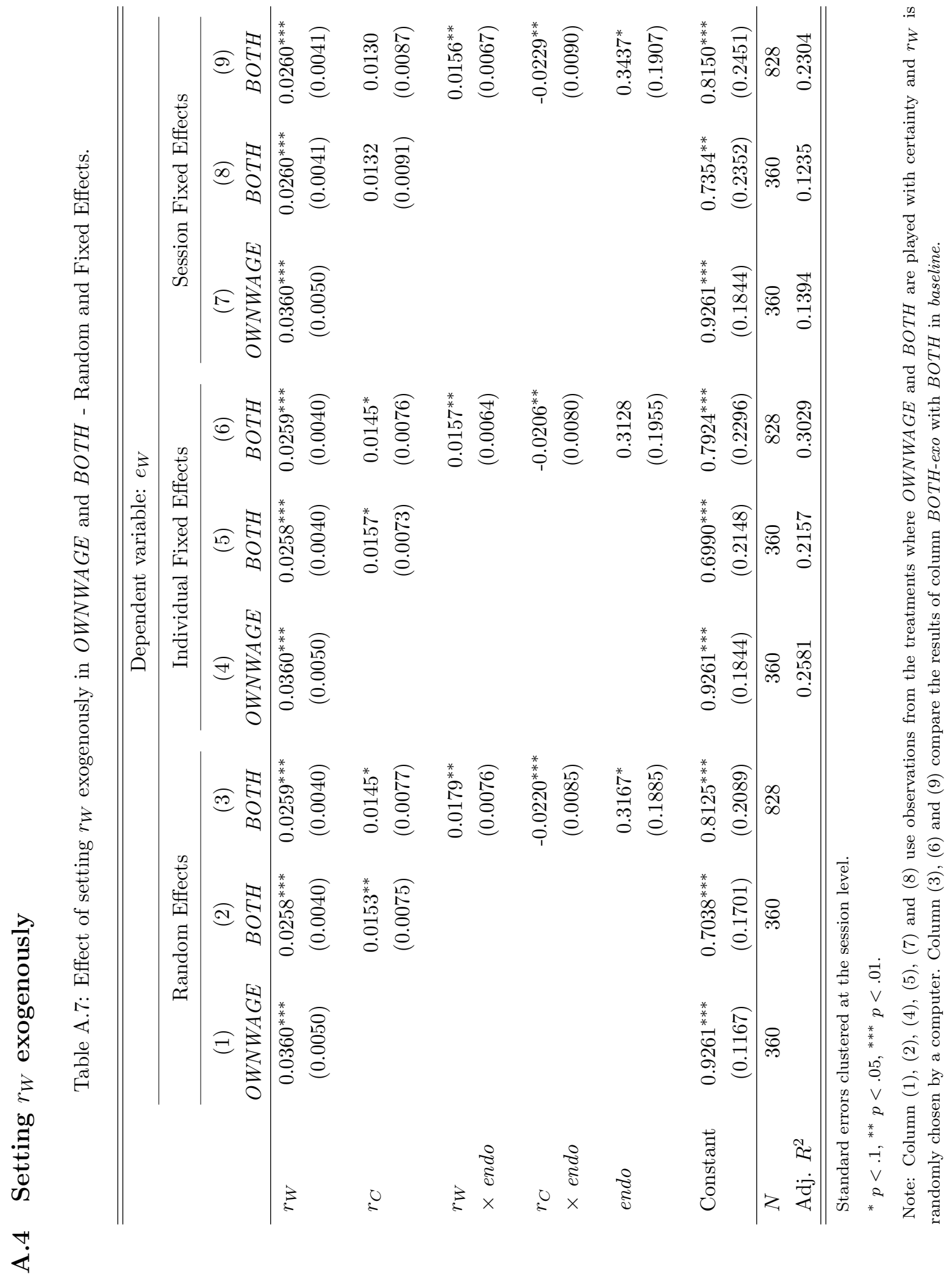




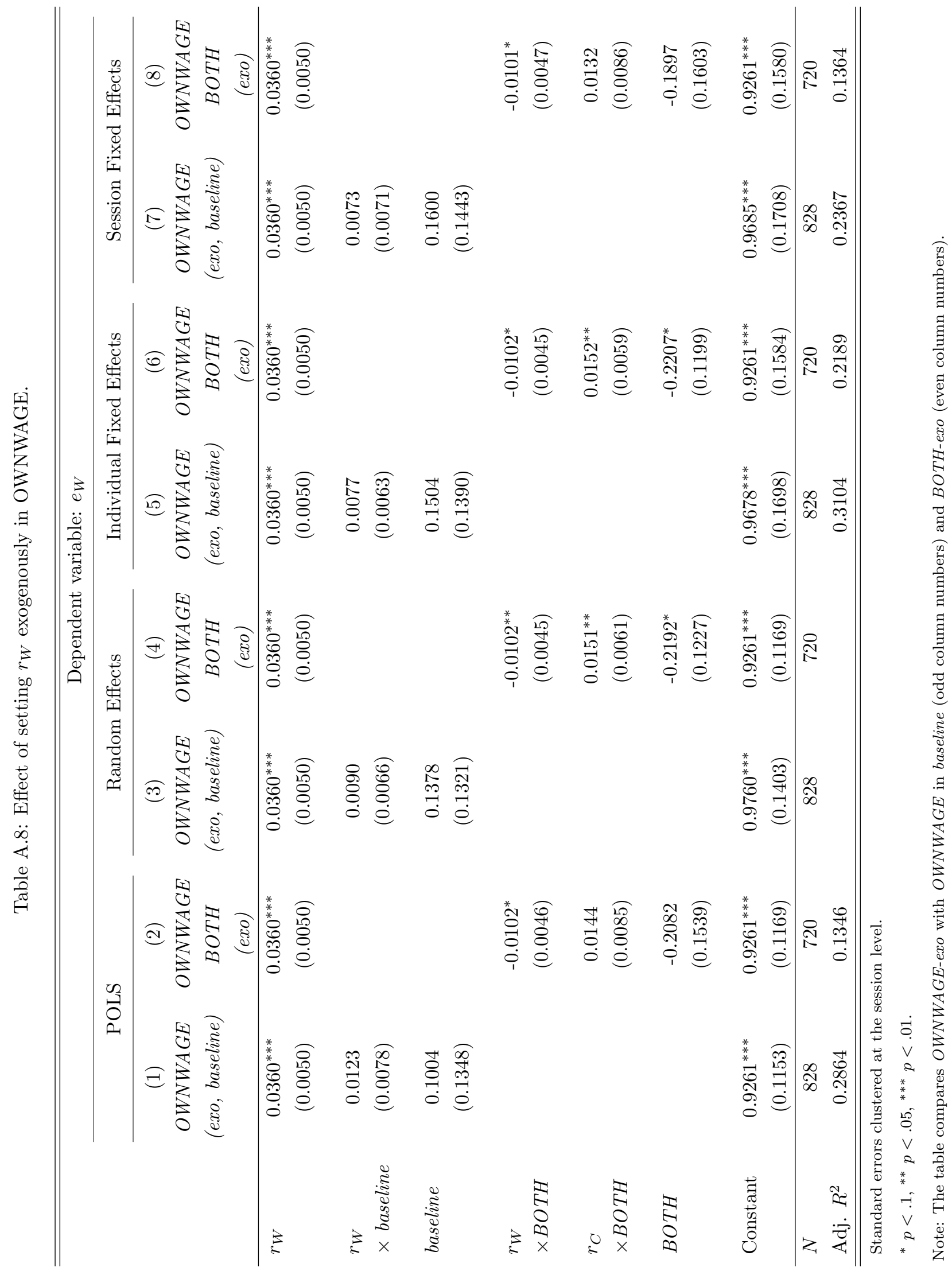


Table A.9: Effect of wages on effort if $B O T H$ is played with certainty.

\begin{tabular}{|c|c|c|c|c|c|c|}
\hline & \multicolumn{6}{|c|}{ Dependent variable: $e_{W}$} \\
\hline & \multicolumn{2}{|c|}{ POLS } & \multicolumn{2}{|c|}{ Random Effects } & \multirow{3}{*}{ 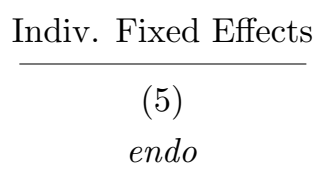 } & \multirow{3}{*}{$\frac{\text { Session Fixed Effect }}{(6)}$} \\
\hline & $(1)$ & $(2)$ & $(3)$ & $(4)$ & & \\
\hline & endo & exo, endo & endo & exo, endo & & \\
\hline \multirow[t]{2}{*}{$r_{W}$} & 0.0135 & $0.0135^{*}$ & 0.0163 & $0.0168^{*}$ & 0.0186 & 0.0046 \\
\hline & $(0.0086)$ & $(0.0073)$ & $(0.0114)$ & $(0.0100)$ & $(0.0140)$ & $(0.0070)$ \\
\hline \multirow[t]{2}{*}{$r_{C}$} & $0.0574^{* * *}$ & $0.0574^{* * *}$ & $0.0416^{* * *}$ & $0.0386^{* * *}$ & 0.0276 & $0.0566^{* *}$ \\
\hline & $(0.0056)$ & $(0.0047)$ & $(0.0053)$ & $(0.0055)$ & $(0.0123)$ & $(0.0059)$ \\
\hline$r_{W}$ & & 0.0124 & & 0.0090 & & \\
\hline$\times$ exo & & $(0.0083)$ & & $(0.0108)$ & & \\
\hline$r_{C}$ & & $-0.0430^{* * *}$ & & $-0.0232^{* *}$ & & \\
\hline$\times$ exo & & $(0.0096)$ & & $(0.0093)$ & & \\
\hline \multirow[t]{2}{*}{ exo } & & -0.3183 & & $-0.5055^{*}$ & & \\
\hline & & $(0.2901)$ & & $(0.2932)$ & & \\
\hline \multirow[t]{2}{*}{ Constant } & $1.0362^{*}$ & $1.0362^{* * *}$ & $1.1817^{* * *}$ & $1.2096^{* * *}$ & $1.3139^{*}$ & $1.3412^{* *}$ \\
\hline & $(0.2628)$ & $(0.2214)$ & $(0.2808)$ & $(0.2398)$ & $(0.3424)$ & $(0.3066)$ \\
\hline$N$ & 72 & 432 & 72 & 432 & 72 & 72 \\
\hline $\operatorname{Adj} . R^{2}$ & 0.2844 & 0.1665 & & & 0.2125 & 0.1893 \\
\hline
\end{tabular}

Standard errors clustered at the session level.

${ }^{*} p<.1,{ }^{* *} p<.05,{ }^{* * *} p<.01$.

Note: The table uses treatments where BOTH is played with certainty and $r_{W}$ is chosen by the manager. In column (2) and (4) this is compared to treatments where BOTH is played with certainty and $r_{W}$ is randomly determined by the computer. Note that this comparison cannot be run with Fixed Effects models as the dummy exo does not vary within individuals or within sessions.

Surprisingly, $r_{W}$ becomes insignificant if $B O T H$ is played with certainty and both wages are set by the manager endogenously in column (1). Instead, $r_{C}$ has a significant positive effect on $e_{W}$. This contradicts previous findings. There is no plausible explanation why workers should react stronger toward their coworker's wage if BOTH is played with certainty. Coefficients of this specification are also highly sensitive to introducing fixed and random effects (column (3), (5) and (6)). We cannot rule out that this result is rooted in the low number of observations $(N=72)$ or the fact that this setting is played only in the last four periods of session 1-3 where we observe a severe downwards trend that might bias our results (see figure 4.1). 
Table A.10: Effect of $r_{W}$ on effort if $O W N W A G E$ is played with certainty.

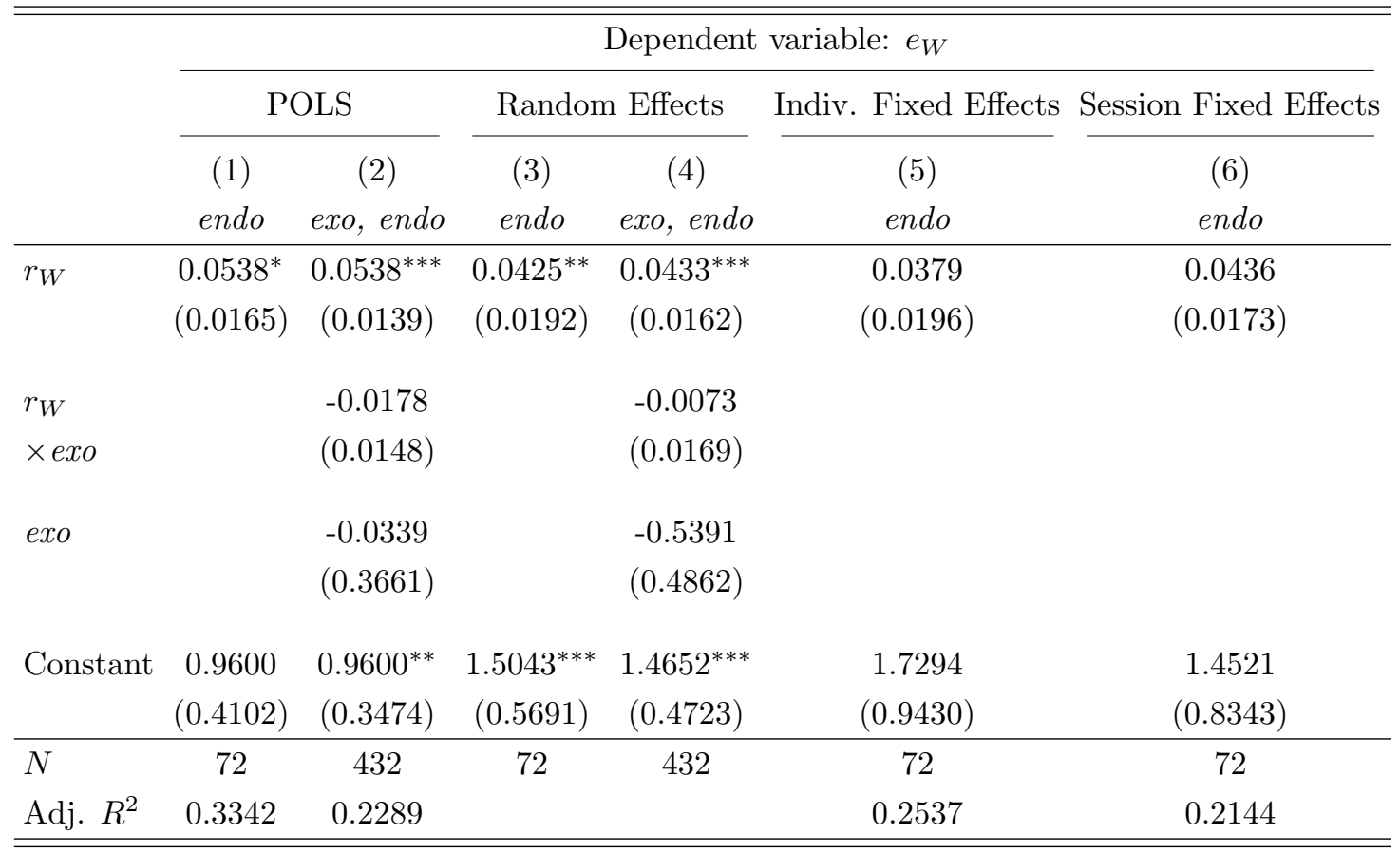

Standard errors clustered at the session level.

${ }^{*} p<.1,{ }^{* *} p<.05,{ }^{* * *} p<.01$.

Note: The table uses treatments where $O W N W A G E$ is played with certainty and $r_{W}$ is chosen by the manager. In column (2) and (4) this is compared to treatments where $O W N W A G E$ is played with certainty and $r_{W}$ is randomly determined by the computer. Note that this comparison cannot be run with Fixed Effects models as the dummy exo does not vary within individuals or within sessions. 


\section{B Indices}

\section{B.1 Reciprocity Index}

The reciprocity index by Dariel and Riedl (2017) measures the extent of the employees reciprocation. It is defined as

$$
R I_{i}=\frac{\sum_{k=0}^{M}\left(e_{k i}-\underline{\mathrm{e}}\right)}{M(\bar{e}-\underline{\mathrm{e}})}
$$

$e_{k i}$ is the effort individual $i$ chooses for wage $w=k$, $\underline{\mathrm{e}}=1$ is the minimum effort, $\bar{e}=10$ is the maximum effort. $M$ is the number of possible wages - thus, the number of decisions an employee has to make ( $M=21$ in our setting).

\section{B.2 Inequality aversion}

To control for the individual degree of inequality aversion, participants were solicited to indicate their preferences in a modified dictator game (MDG) and an ultimatum game (UG) at the end of the experiment. Results are used to calculate parameters of guilt and envy as suggested by Blanco et al. (2011). They enter the following utility function $U_{i}$ of individual $i$ :

$$
U_{i}(\mathbf{x})=x_{i}-\alpha_{i} \max \left\{x_{j}-x_{i}, 0\right\}-\beta_{i} \max \left\{x_{i}-x_{j}, 0\right\}, \quad i \neq j
$$

The utility function was introduced by Fehr and Schmidt (1999). Individuals derive positive utility from their own payoff $x_{i}$. The difference between their own and their opponent's payoff $x_{j}$ enters the utility function negatively. The second term of the equation $\alpha_{i} \max \left\{x_{j}-x_{i}, 0\right\}$ captures disutility from disadvantageous inequality $\left(x_{j}>x_{i}\right)$, the third term $\beta_{i} \max \left\{x_{i}-x_{j}, 0\right\}$ captures disutility from advantageous inequality $\left(x_{i}>x_{j}\right)$.

\section{B.2.1 Disadvantageous inequality}

To estimate the envy parameter $\alpha$ for disadvantageous inequality, answers from the UG (figure B.1) are used. In the UG, individuals are offered eleven payoff allocations between player A and B. For each of them they had to decide whether to accept or reject the offer. Allocations ranged from $(10,0)$ over $(5,5)$ to $(0,10)$. In case of rejection both participants get a zero payoff. 
Figure B.1: Screenshot of the Ultimatum Game.

\begin{tabular}{|c|c|c|}
\hline \multicolumn{3}{|c|}{ Wir erinnern Sie daran, dass, sofern Sie annehmen, sowohl Person A als auch Person B den entsprechenden Betrag erhalten. Sofern sie ablehnen, erhalten beide 0.} \\
\hline Entscheidung & Aufteilung (Gewinn A - Gewinn B) & Ihre Wahl \\
\hline Entscheidung 1 & $10-0$ & akzeptieren $r r$ ablehnen \\
\hline Entscheidung 2 & $9-1$ & akzeptieren $\sim c$ ablehnen \\
\hline Entscheidung 3 & $8-2$ & akzeptieren $\subset \subset$ ablehnen \\
\hline Entscheidung 4 & $7-3$ & akzeptieren $\sim r$ ablehnen \\
\hline Entscheidung 5 & $6-4$ & akzeptieren $\sim c$ ablehnen \\
\hline Entscheidung 6 & $5-5$ & akzeptieren $\sim c$ ablehnen \\
\hline Entscheidung 7 & $4-6$ & akzeptieren $\sim\ulcorner$ ablehnen \\
\hline Entscheidung 8 & $3-7$ & akzeptieren $\sim r$ ablehnen \\
\hline Entscheidung 9 & $2-8$ & akzeptieren $\sim r$ ablehnen \\
\hline Entscheidung 10 & $1-9$ & akzeptieren $\sim \subset$ ablehnen \\
\hline \multirow[t]{2}{*}{ Entscheidung 11} & $0-10$ & akzeptieren $\sim r$ ablehnen \\
\hline & & \\
\hline
\end{tabular}

According to the model of inequality aversion, subjects are expected to reject highly unequal offers, and thus prefer a zero payoff for both players over an unequal payoff distribution where they are worse off than their counterpart. To define the degree of inequality aversion, the point, where individuals switch from rejection to acceptance in the ultimatum game, is sought. For the first 5 decisions player $\mathrm{B}$ is behind, hence according to equation (3) B's utility reads $U_{B}=\pi_{B}-\alpha_{B}\left(10-\pi_{B}-\pi_{B}\right)$. Player A's payoff is denoted by $\pi_{A}=10-\pi_{B}$. At the switching point $\pi_{B}=s_{B}$, the utility of acceptance is equal to the utility of rejection and receiving a zero payoff: $U_{B}=s_{B}-\alpha_{B}\left(10-s_{B}-s_{B}\right)=0$. Thus, the envy parameter can be defined as $\alpha_{B}=\frac{s_{B}}{10-2 s_{B}}$. The switching point is approximated as the average between the highest offer rejected and the lowest offer accepted, which equals the lowest acceptable offer minus 0.5 .

Note that in order to calculate $\alpha$, offers above 5 do not need to be taken into account since this constitutes advantageous inequality.

Individuals who did not accept all offers below $(5,5)$ are assumed to have a maximal aversion against disadvantageous inequality which is $\alpha=4.5$. On the other hand, subjects who accepted any offer, do not seem to have a preference for equality and hence $\alpha=0$.

Any individual with inconsistent preferences, is ruled out from the analysis. This applies to individuals who accept an unequal distribution but reject another distribution with less inequality and higher payoff for themselves. 


\section{B.2.2 Advantageous inequality}

Similarly, $\beta$ is estimated to measure the refusal of advantageous inequality. We use the switching point of the MDG (figure B.2). In the MDG, subjects have to make eleven decisions between two payoff distributions. In each of the eleven choices, they have to decide between an unequal distribution where they receive 10 and their partner receives 0 and an equal split ranging from $(0,0)$ in the first decision to $(10,10)$ in the last decision.

Figure B.2: Screenshot of the modified Dictator Game.

\begin{tabular}{|c|c|c|c|c|c|c|}
\hline \multicolumn{7}{|c|}{$\begin{array}{l}\text { Stellen Sie sich vor, dass Sie (Spieler A) zusammen mit einem anderen Spieler (Spieler B) in einer Gruppe sind. } \\
\text { Tun Sie für jede der } 11 \text { folgenden Entscheidungen so, als ob Sie Person A wären und wählen Sie die linke oder die rechte Verteilung. }\end{array}$} \\
\hline Entscheidung & Gewinn A & Gewinn B & Ihre Wahl & Gewinn A & Gewinn B & \\
\hline Entscheidung 1 & 10 & 0 & links $\sim \subset$ rechts & 0 & 0 & \\
\hline Entscheidung 2 & 10 & 0 & links $\sim \sim$ rechts & 1 & 1 & \\
\hline Entscheidung 3 & 10 & 0 & links $\sim \subset$ rechts & 2 & 2 & \\
\hline Entscheidung 4 & 10 & 0 & links $\sim \subset$ rechts & 3 & 3 & \\
\hline Entscheidung 5 & 10 & 0 & links $\sim \subset$ rechts & 4 & 4 & \\
\hline Entscheidung 6 & 10 & 0 & links $\sim \sim$ rechts & 5 & 5 & \\
\hline Entscheidung 7 & 10 & 0 & links $\sim \sim$ rechts & 6 & 6 & \\
\hline Entscheidung 8 & 10 & 0 & links $\sim \subset$ rechts & 7 & 7 & \\
\hline Entscheidung 9 & 10 & 0 & links $\subset \subset$ rechts & 8 & 8 & \\
\hline Entscheidung 10 & 10 & 0 & links $\sim \sim$ rechts & 9 & 9 & \\
\hline Entscheidung 11 & 10 & 0 & links $\sim c$ rechts & 10 & 10 & \\
\hline & & & & & & ok \\
\hline
\end{tabular}

In this setting, participants are assigned to the role of player A. The switching point $s_{A}$, where they are indifferent between an equal split e.g., $(6,6)$ and the payoff allocation $(10,0)$ yields the guilt parameter $\beta$. At this point utility from equation (3) reads as $U_{A}=10-\beta(10-0)=s_{A}$ and thus $\beta=1-\frac{s_{A}}{10}$. Again, the switching point is the lowest egalitarian allocation accepted minus 0.5.

Individuals who always chose the equal split are assigned the maximum guilt parameter $\beta=1$, while individuals who always prefer $(10,0)$ have $\beta=0$ since they do not show any concern for their partner's outcome.

Furthermore, any individual with inconsistent preferences was excluded from the analysis. In this case this corresponds to individuals that prefer an egalitarian outcome $\pi_{A}=\pi_{B}$ over $(10,0)$ but prefer $(10,0)$ over another equal offer with higher payoffs. 


\section{Overview experiment}

Table C.1: Overview on experimental setting in session 1-3.

\begin{tabular}{l||l|l|l|l}
\hline \hline & Intro & baseline & certain & certain \\
\hline \hline Rounds & 4 & 18 & 4 & 4 \\
\hline Wages & $r_{W} \in[0,100]$ & $r_{W} \in[0,100]$ & $r_{W} \in[0,100]$ & $r_{W} \in[0,100]$ \\
& $r_{C} \in[0,100]$ & $r_{C} \in[0,100]$ & $r_{C} \in[0,100]$ & $r_{C} \in[0,100]$ \\
\hline Effort & $e_{W} \in[1,10]$ & $e_{W} \in[1,10]$ & $e_{W} \in[1,10]$ & $e_{W} \in[1,10]$ \\
& $e_{C} \in[1,10]$ & $e_{C}=4$ & $e_{C}=4$ & OWNWAGE \\
\hline Treatment & BOTH & $\begin{array}{l}\text { BOTH } \\
\text { OWNWAGE }\end{array}$ & OWOTH \\
& & COWORKER & no & yes \\
\hline $\begin{array}{l}\text { Treatments } \\
\text { played } \\
\text { with certainty }\end{array}$ & yes & no & \\
\hline \hline
\end{tabular}

BOTH: employees observe both wages

$O W N W A G E$ : employees observe their own wages

COWORKER: employees observe coworker's wages 
Table C.2: Overview on experimental setting in session 4-13.

\begin{tabular}{l||l|l|l|l}
\hline \hline & Intro & baseline & certain & certain \\
\hline \hline Rounds & 1 & 18 & 6 & 6 \\
\hline Wages & $r_{W} \in[0,100]$ & $r_{W} \in[0,100]$ & $\begin{array}{l}r_{W} \in[10,40,60] \\
(\text { exogenous })\end{array}$ & $\begin{array}{l}r_{W} \in[10,40,60] \\
(\text { exogenous })\end{array}$ \\
& $r_{C} \in[0,100]$ & $r_{C} \in[0,100]$ & $r_{C} \in[0,100]$ & $r_{C} \in[0,100]$ \\
\hline Effort & $\begin{array}{l}\text { Strategy method } \\
e_{W} \in[1,10]\end{array}$ & $e_{W} \in[1,10]$ & $e_{W} \in[1,10]$ & $e_{W} \in[1,10]$ \\
\hline $\begin{array}{l}\text { Treatment } \\
e_{C} \in[1,10]\end{array}$ & OWNWAGE & $\begin{array}{l}e_{C}=4 \\
\text { BOTH }\end{array}$ & $e_{C}=4$ & $e_{C}=4$ \\
\hline $\begin{array}{l}\text { Treatments } \\
\text { played } \\
\text { with certainty }\end{array}$ & yes & OWNWAGE & OWNWAGE & BOTH \\
\hline \hline
\end{tabular}

BOTH: employees observe both wages

$O W N W A G E$ : employees observe their own wages

COWORKER: employees observe coworker's wages

Note: The order of the treatments baseline and certain varied between sessions. 